UNIVERSIDADE DE SÃO PAULO

INSTITUTO DE FÍSICA DE SÃO CARLOS

DEPARTAMENTO DE FÍSICA E CIÊNCIA DOS MATERIAIS

\title{
APRISIONAMENTO MAGNÉTICO DE UM GÁS NEUTRO DE ÁTOMOS DE SÓDIO PARA A REALIZAÇÃO DA CONDENSAÇÃO DE BOSE-EINSTEIN
}

\author{
Edson de O. Mosman Junior
}

Orientador: Prof. Dr. Luis Gustavo Marcassa

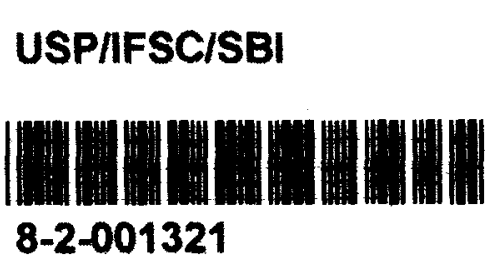

Dissertação apresentada ao Instituto de Física de São Carlos, Universidade de São Paulo, para obtenção do título de mestre em ciências: Física Básica

São Carlos - São Paulo

2000 
Mosman Junior, Edson de Oliveira

“Aprisionamento Magnético de um gás neutro de átomos de sódio para a realização da condensação de bose-einstein"/ Edson de Oliveira Mosman Junior - São Carlos, 2000

Dissertação (Mestrado) - Instituto de Física de São Carlos da Universidade de São Paulo, 2000 - páginas: 080

Área: Física Básica

Prof. Dr. Luis Gustavo Marcassa

1. Aprisionamento, 2. Átomos de sódio

I. Título 
MEMBROS DA COMISSÃO JULGADORA DA DISSERTAÇÃO DE MESTRADO DE EDSON DE OLIVEIRA MOSMAN JUNIOR APRESENTADA AO INSTITUTO DE FÍSICA DE SÃO CARLOS, DA UNIVERSIDADE DE SÃO PAULO, EM 25 DE ABRIL DE 2000

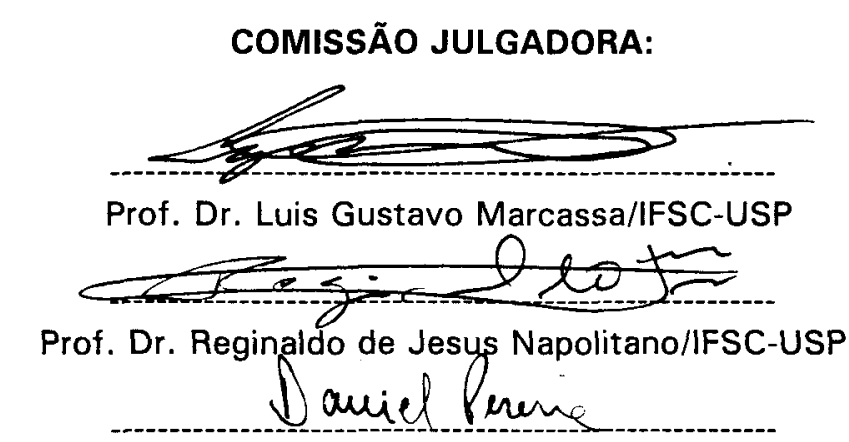

Prof. Dr. Daniel Pereira/UNICAMP 


\section{AGRADECIMENTOS}

Ao professor Luis Gustavo Marcassa pela valiosa orientação e pelas filosóficas e profundas discussões...

À minha mãe, eu não preciso falar nada...Freud já disse tudo..

Ao Serginho, pois juntos tentamos dominar o incrível mundo dos IGBTs e por ouvirmos pacientemente ..."e aí, esse negócio sai ou não sai ???"...

Ao engenheiro e mestre Carlos, também conhecido por "Ooh...Carlos?" pela ajuda desde altas tensões até altas correntes...

Ao Phelipe pelo auxílio durante todo o experimento e pela troca cultural...

Ao Daniel por ter lido a dissertação e feito sujestões...

À todos do grupo de Óptica ...Isabel, Glaucia, Gilberto, Evaldo, Rui, Anderson ...Cleber, Joatan, Carlos, Fernandão, Leonardo (bóra-bóra-bóra), Newton, Gugs, Ricardo, Marcelo, Kilvia, André, Marília, Tiago, Leandro, Wander e seu irmão Wânius(da ÓóÓpticaaa), Sérgio G., Cláudia, Flavião, Cléo...

As plenas e poderosas Cida, Mônica, Salete e Cristina..

Aos meus irmãos Andrei, Leandro e Déborah pela excêntrica família que formamos...

Aos cavaleiros do apocalipse: Eric, Gustavo e Rodrigo pelas aventuras e batalhas...

À minha amiga e eterna psicóloga Renata ...

À Sandra, Flávia e a Dona Cleide ... 
À Sandrinha pelo apoio em todos os momentos e por ter me mostrado uma maneira toda diferente de ver e encarar a vida, de uma forma mais arquitetônica..

Ao Álvaro e a Diva pela segunda família que tenho, sempre acolhedores...

Ao Paulo (O Herói do parto), Suely e Biazinha pela amizade ...

Aos meus contemporâneos Claudia e Frederico..

Ao Pop e Minimalista Juliano pelos pães\&doces que ficavam na geladeira e por ter me apresentado ao Andy...

Ao Patric, Valéria (P.M.) e ao Fábio (Go-Go) pelas ótimas risadas...

À galera do alojamento ... a jovem guarda: Mineiro, Presunto, Salame, Zig, Biro, Ericão, Tigrão, Carlão, Soró, Pente, Douglas, Reg, Ubaldo, Catunda, Marie, Luciana, Allan P., Mun-há, Campineiro, Rafael, Fabiano, Carioca, Sombra, Erica...e a velha guarda: Chico Bento, Liziane, Fabiana, Wally\&Japa\&Grilo, Gal, Ceará, Teodora, Tereza, Daniel, Piu-Piu....e mais um montão de gente que não me lembrei agora..

Ao CNPq pelo apoio financeiro. 
O amor, o trabalho e o conhecimento são as fontes da nossa vida. Deveriam também governá-la.

Wilheim Reich 
À minha avó, Lourdes, à minha mãe, Lígia, e à minha irmã, Déborah... 


\section{ÍNDICE}

Resumo.............................................................................................

Lista de abreviaturas..................................................................ii

Lista de figuras..................................................................................iii

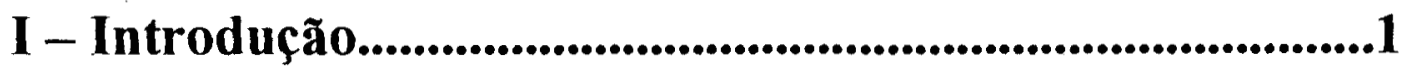

II - Técnicas de Aprisionamento.................................................8

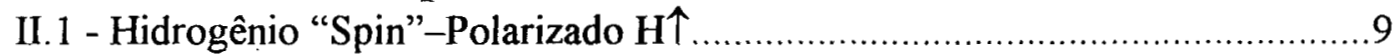

II. I.a - Aprisionamento Magnético.............................................................II

II. I.b - Resfriamento evaporativo............................................................... 17

II. 2 - Resfriamento e Aprisionamento de Metais Alcalinos..............................19

II. 2.a - Feixe Atômico................................................................................ 20

II.2.b - Melaço Óptico............................................................................2I

II.2.c - Aprisionamento Magneto-óptico MOT..............................................22

II.2.d - Configurações de Aprisionamentos Magnéticos..................................26

II.2.d.I - Configuração Ioffe-Pritchard (I.P.) ...............................................26

II.2.d.2 - Compressão Adiabática........................................................ 30

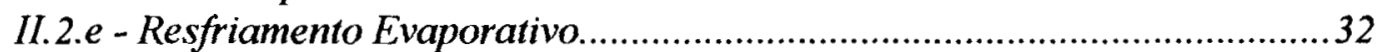

III - Montagem Experimental...................................................34

"III.1 - Seqüência Temporal do Experimento........................................... 34

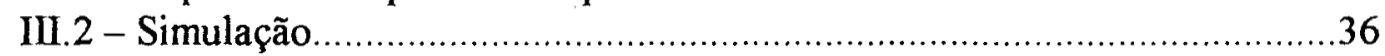

III.3 - Sistema Mecânico do Feixe Atômico...................................................... 39

III. 4 - Sistema Mecânico do MOT ........................................................... 41

III. 5 - Sistema Eletro-eletrônico do MOT ..................................................42 42

III. 6- Sistema Mecânico da Armadilha Magnética..........................................43

III.7 - Sistema Eletro-eletrônico da Armadilha Magnética...............................44

III. 7.a - Sistema de Chaveamento................................................................45

III. 7.a.I - Configuração..........................................................................4 46

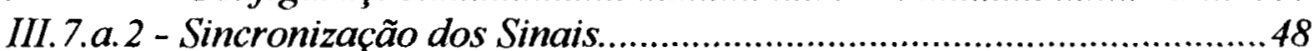

III. 7.b - Sistema de Compressão...........................................................50

IV - Caracterização e Aprisionamento.................................53

IV. 1- Caracterização do Sistema Eletro-eletrônico..........................................53

IV.1.a- Caracterização do Sistema de MOT..................................................5. 53

IV.1.b-Caracterização da Armadilha Magnética..............................................55

IV.2-Tempo de Vida e Imagem...........................................................59

V-Conclusões...................................................................62

VI - Referências.....................................................................65 


\section{RESUMO}

Para atingir o regime de condensação de Bose-Einstein (CBE) em gases de metais alcalinos são necessárias várias etapas: feixe desacelerado, aprisionamento magneto-óptico, aprisionamento magnético e por fim o resfriamento evaporativo. Como estamos interessados em atingir o regime de CBE precisamos nos preocupar com as várias etapas intermediárias. Neste trabalho apresentaremos a construção e caracterização de uma armadilha magnética para um gás de átomos neutros de sódio. O sistema optado por nós foi o "folha de trevo", com o qual conseguimos a seguinte configuração de campos magnéticos: 140 gauss de campo de fundo na direção axial, 117 gauss $/ \mathrm{cm}$ de gradiente radial e 106 gauss $/ \mathrm{cm}^{2}$ de curvatura na direção axial. Para gerarmos esta configuração de campo e desligarmos estes campos em um tempo menor que um milisegundo foi necessária a construção de um sistema de chaveamento e controle que será descrito e caracterizado neste trabalho. Com este sistema em funcionamento observamos aproximadamente $10^{8}$ átómos aprisionados e um tempo de 1 segundo. Além disso, observamos os átomos adaptando-se a diferentes formas de potenciais de aprisionamento. 


\section{LISTA DE ABREVIATURAS}

CBE - Condensação de Bose-Einstein

MOT - Armadilha Magneto-óptica

IP - Ioffe-Pritchard

RF - Rádio Freqüência

MOSFET - Metal Oxide Semiconductor Field-Effect

Transistor

IGBT - Insulated Gate Bipolar Transistor

$\mathrm{V}_{\mathrm{DS}}$ - Tensão Dreno-Source

TTL - Transistor-Transistor Logic

CCD - Charged Coupled Device 


\section{LISTA DE FIGURAS}

FIGURA 1: Estados hiperfinos do átomo de hidrogênio na presença de um campo magnético.

FIGURA 2: Movimento de precessão de um átomo com momento magnético $\mu_{\mathrm{m}}$ na presença de um campo magnético estático. No centro da figura está a oscilação de um átomo confinado

FIGURA 3: Processo de resfriamento evaporativo em uma distribuição de velocidades:(a) distribuição a uma temperatura $T_{1},(b)$ distribuição truncada e (c) nova distribuição após a retermalização a uma temperatura $T_{2}, T_{2}<T_{1}$

FIGURA 4: Resfriamento evaporativo de átomos aprisionados magneticamente. Abaixando o potencial vamos eliminando os átomos mais quentes...............................18

FIGURA 5: Átomos sendo desacelerados por um feixe de "laser" contra propagante.......21

FIGURA 6: (a) Abertura Zeeman das energias, (b) Bobinas na configuração para gerar campo linear e as polarizações adequadas para construção do MOT.

FIGURA 7: Estrutura hiperfina do átomo de sódio.

FIGURA 8: (a) Representação do "spot" do feixe "laser" para o MOT comum, (b) Configuração do "spot" para a obtenção do "dark MOT".

FIGURA 9: Sistema de bobinas na configuração loffe-Pritchard.

FIGURA 10: Sistema de bobinas na configuração folha de trevo, bobinas de curva e bobinas de compressão.

FIGURA 11: (a) Potencial com um alto valor de $\mathrm{B}_{0}$, potencial pouco confinante, (b) potencial comprimido, baixo valor de $\mathrm{B}_{0}$.

FIGURA 12: Resfriamento evaporativo em metais alcalinos, no caso sódio, induzido por rádio-freqüência

FIGURA 13: Abertura Zeeman das linhas do átomo de sódio e as transições para a realização do resfriamento evaporativo 
FIGURA 15: Simulação dos campos gerados pelas bobinas para o aprisionamento magnético, folha de trevo (azul), curvatura (verde), compressão (vermelho) e o campo total (círculos) .0 corte da esquerda mostra o campo em $z$, e o da direita o corte na direção radial, $\mathrm{I}_{\mathrm{C}}=70 \mathrm{~A}$.

FIGURA 16: Simulação dos campos gerados pelas bobinas para o aprisionamento magnético . $\mathrm{I}_{\mathrm{C}}=90 \mathrm{~A}$. $\mathrm{I}_{\mathrm{TOTAL}}=285 \mathrm{~A}$

FIGURA 17: Simulação dos campos gerados pelas bobinas para o aprisionamento Magnético. $\mathrm{I}_{\mathrm{C}}=100 \mathrm{~A}$. $\mathrm{I}_{\text {TOTAL }}=285 \mathrm{~A}$

FIGURA 18: Simulação dos campos gerados pelas bobinas para o aprisionamento magnético. $I_{C}=120 A$. $I_{\text {TOTAL }}=285 \mathrm{~A}$.

FIGURA 19: Visão geral do sistema de resfriamento do feixe atômico mostrando toda trajetória do feixe até chegar na câmara de MOT

FIGURA 20: Câmara de MOT onde será feito o aprisionamento magneto-óptico e também o aprisionamento magnético.

FIGURA 21: Sistema de controle das bobinas de MOT e a configuração do sistema elétrico .42

FIGURA 22: Configuração espacial das bobinas em relação à câmara. .43

FIGURA 23: (a) Circuito de controle dos IGBTs, (b) Circuito de atraso 49

FIGURA 24: Circuito de controle do MOSFET para que tenhamos uma variação linear de corrente nas bobinas de compressão

FIGURA 25: Visão geral do sistema elétrico das bobinas e os sistemas de controle do mesmo.

FIGURA 26: $V_{D S}$ no MOSFET do sistema de chaveamento do MOT: (a) e (b) quando o sistema está sendo desligado e com resolução temporal diferente, (c) e (d) Sistema sendo ligado.

FIGURA 27: $V_{D S}$ no IGBTl e tensão sobre o resistor de carga: (a) quando fechamos o circuito, (b) quando abrimos o circuito

FIGURA 28: $V_{D S}$ no IGBT2 e tensão sobre o resistor de teste: (a) quando fechamos o circuito, (b) quando abrimos o circuito. 
FIGURA 29: $V_{D S}$ dos IGBTs 1 e 2, quando as bobinas estão sendo ligadas com resolução

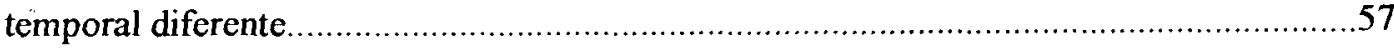

FIGURA 30: $V_{D S}$ dos IGBTs 1 e 2, quando as bobinas estão sendo desligadas com

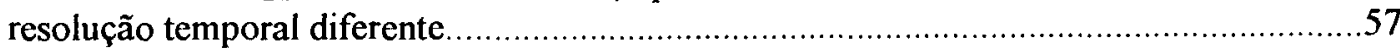

FIGURA 31: Flutuação de corrente da fonte durante o chaveamento, (a) quando as bobinas estão sendo ligadas, (b) quando as bobinas estão sendo desligadas..................................58

FIGURA 32: Curva de calibração do sistema de compressão..........................................59

FIGURA 33: Medida do tempo de vida da armadilha magnética, número de átomos em unidades arbitrárias em função do tempo, $\tau \approx 1 \mathrm{~s}$..

FIGURA 34: Imagem da armadilha magnética variando-se a corrente nas bobinas de compressão, de $70 \mathrm{~A}$ a $140 \mathrm{~A}$. Ao lado das imagens temos os perfis de intensidade das imagens. 


\section{I - Introdução}

Sempre foi grande o interesse da Física em poder explicar o mundo macroscópico a partir do entendimento de seus constituintes microscópicos. Assim, um dos grandes sucessos da ciência foi o estabelecimento da atomística. Partindo da hipótese que tudo é constituído de entidades extremamente pequenas, chamadas de átomos, fomos capazes de explicar várias propriedades do mundo macroscópico. Historicamente, a explicação das propriedades de um gás, como pressão e temperatura e sua relação com o volume, foi o primeiro grande sucesso em termos de conectar o mundo microscópico com o mundo macroscópico. Muitos outros exemplos desta conexão do micromundo com o macromundo foram responsáveis pela origem da ciência moderna, ricamente exemplificada pela matéria condensada, biologia molecular e etc.

O comportamento do mundo microscópico é diferente daquele que estamos acostumados em nosso dia a dia. Quando descemos a dimensões tão pequenas quanto o tamanho do átomo, a matéria possui o chamado comportamento quântico. Nesse

regime, quando vamos estudar uma partícula isolada, na verdade, devemos nos preocupar com a função de onda associada a esta partícula. A interpretação física 
desse sistema é bem diferente daquela que estamos acostumados a fazer com o mundo macroscópico.

Para sistemas com apenas uma partícula, como por exemplo: poço de potencial, oscilador e átomo de Hidrogênio, podemos resolvê-los analiticamente utilizando a mecânica quântica. Entretanto, para sistemas com duas ou mais partículas o problema não é tão simples assim. Quando temos um sistema com duas partículas, não interagente, a única afirmação que podemos fazer sobre este é em relação à simetria da função de onda associada a estas partículas. Afirmação esta que é conhecida como principio de Pauli. Para partículas com "spin" semi-inteiros, denominadas de Férmions, as funções de onda serão anti-simétricas. Para partículas com "spin" inteiros (Bósons), as funções de onda serão simétricas. Em termos estatísticos, partículas com funções de onda anti-simétricas (Férmions), não podem ocupar o mesmo estado quântico de um sistema e sua distribuição está sujeita à estatística de Fermi-Dirac. Já os Bósons, que possuem funções de onda simétricas, podem ocupar o mesmo estado quântico de um sistema e são regidos pela estatística de Bose. Lembrando que as partículas são indistinguíveis quanticamente, então, todo o universo que nos cerca é conseqüência desses dois fatos: simetrias das funções de onda e indistingüibilidade das partículas.

Vamos imaginar um sistema de particulas, não interagente, por exemplo, um gás confinado em uma caixa. Este sistema não apresenta um espectro contínuo de energia, somente valores discretos são possíveis. A uma temperatura $\mathrm{T}$, as partículas que constituem este sistema apresentam-se estatisticamente distribuídas pelos vários estados de energia. Todas as propriedades macroscópicas serão conseqüências da 
distribuição estatística dessas várias partículas contidas nesses vários estados de energia. Nenhum desses estados apresenta-se ocupado com um número macroscópico de partículas, de modo que nenhum dos estados contribui diferentemente para as propriedades termodinâmicas do sistema. A contribuição é somente devido ao seu peso estatístico.

Einstein previu que um gás constituído por bósons poderia, em baixas temperaturas, apresentar uma ocupação macroscópica no seu estado de mais baixa energia (número esse da ordem do número total de partículas do sistema). As partículas neste estado específico contribuem para as propriedades do gás de forma diferente das demais, ou seja, com um peso estatístico maior. Esta ocupação macroscópica do estado fundamental do sistema provoca mudanças de comportamento em relação às propriedades termodinâmicas do sistema (pressão, viscosidade, condutividade térmica, etc.) caracterizando uma transição de fase. Como foi prevista por Einstein (1925), usando a estatística de Bose, esta transição de fase é denominada de condensação de Bose-Einstein (CBE). A CBE é uma ocupação macroscópica do estado fundamental de um sistema $[1,2]$.

Uma outra visão pictórica sobre a condensação de Bose-Einstein, nesse mesmo sistema, é a seguinte: cada partícula desse gás tem um comprimento de onda térmico de De Broglie, $\lambda_{\mathrm{dB}}$, associado a ela. Essa onda associada à partícula pode ser interpretada como a incerteza na posição associada com a distribuição térmica de momento. Quanto menor a temperatura $\mathrm{T}$, maior será o comprimento de onda térmico de De Broglie, $\lambda_{\mathrm{dB}}$, associado à partícula. Conforme formos abaixando a temperatura, este gás irá chegar num momento em que à distância entre as partículas 
época ainda não havia sido formulado o princípio de Pauli, assim como os conceitos sobre indistingüibilidade. Sem falar que a mecânica quântica ainda estava começando a se consolidar. Por volta de 1938, London relacionou a condensação de Bose-Einstein com a superfluidez do ${ }^{4} \mathrm{He}$, depois disso a CBE deixou de ser tratada como mera especulação matemática. Depois de Einstein tivemos inúmeras contribuições teóricas sendo que as mais notáveis foram dadas por: London, Landau, Tisza, Bogoliubov, Penrose, Onsager, Feynman, Lee, Yang, Huang, Beliaev, Pitaevskii e muitos outros.

Até este momento, o único sistema que reunia as condições necessárias para a CBE era o ${ }^{4} \mathrm{He}$ líquido [3], mas este é um sistema altamente interagente e, por isso, de grandes dificuldades para verificações experimentais de teorias e conceitos. Nos dias de hoje, esse é um problema que está em aberto na física moderna. Então, por muito tempo, a realização da $\mathrm{CBE}$ em um sistema pouco interagente e livre das complicações apresentadas no ${ }^{4} \mathrm{He}$ era almejado pelos cientistas para verificações teóricas.

Nos anos 80 foi verificada a CBE em semicondutores, mas mesmo assim, era um sistema com tantas complicações teóricas e experimentais quanto o ${ }^{4} \mathrm{He}$. $\mathrm{O}$ éxciton, que consiste num par elétron-buraco, possui "spin" inteiro sendo então um bóson. A física do éxciton em semicondutores é extremamente rica e interessante e inclui a formação de um elétron-buraco líquido e bi-éxcitons. Há sistemas, o mais notável é o $\mathrm{Cu}_{2} \mathrm{O}[4,5]$, onde os éxcitons formam um gás pouco interagente e com um tempo de vida longo o suficiente para verificar evidências de condensação de Bose-Einstein. 
Também foram durante os anos 80 que a produção e estabilização de hidrogênio $[10,11]$ criou novas perspectivas para a realização da CBE em gases poucos interagentes e, com este estudo, toda uma gama de novas técnicas e teorias foram desenvolvidas. Técnicas essas que, felizmente, puderam ser diretamente aplicadas em sistemas como metais alcalinos. Foi ainda nos anos 80 que foram realizados experimentos como: desaceleração de feixes atômicos, aprisionamento magnético, aprisionamento magneto-óptico e também as primeiras idéias sobre o resfriamento evaporativo. Todas essas técnicas citadas são passos fundamentais para a realização da CBE em gases atômicos pouco interagentes.

Mas foi só durante o ano de 1995 que três grupos [6,7,8], conjugando essas técnicas, observaram pela primeira vez a realização da CBE em átomos de metais alcalinos. Para o sistema com hidrogênio atômico só foi observada a CBE em 1997. Basicamente, em todos esses experimentos a seqüência para a realização da CBE foi: feixe desacelerado, aprisionamento magneto-óptico, aprisionamento magnético, resfriamento evaporativo.

Desde o final dos anos 80 e início dos anos 90 nosso grupo vem participando e contribuindo ativamente no estudo e na compreensão desses sistemas. Assim, como uma seqüência natural estamos também interessados na realização da CBE. Nesse presente trabalho vamos apresentar a construção e caracterização de nosso sistema para o aprisionamento magnético de um gás neutro de sódio. Este sistema é uma fase intermediária de vital importância para a obtenção da CBE.

No capítulo II, apresentaremos uma introdução sobre as atuais técnicas de aprisionamento e resfriamento de vapores atômicos, bem como características 
específicas de alguns sistemas. Por razões históricas vamos apresentar o sistema com hidrogênio atômico e também vamos introduzir alguns conceitos sobre aprisionamento magnético. A configuração de bobinas optada por nós foi à folha de trevo, sendo uma variação da Ioffe-Pritchard que será discutida. Dentro desta configuração vamos nos preocupar com os regimes de operação deste sistema, por exemplo, a compressão adiabática, que será fundamental para termos um resfriamento evaporativo eficiente. Como ultima técnica vamos discutir e exemplificar o resfriamento evaporativo.

Já no capitulo III, será descritas a construção e a simulação das bobinas. Tão importante quanto às técnicas e o sistema, é a seqüência temporal em que elas deverão ocorrer. Por isso levantaremos alguns aspectos sobre a mesma.

Descreveremos a parte mecânica do sistema, bem como suas características. Apresentaremos a configuração elétrica do sistema para conseguirmos a configuração de campo magnético e características necessárias para o aprisionamento e ainda, as simulações do campo a ser gerado.

No capítulo IV, será apresentada uma caracterização em detalhes do sistema elétrico e de seu controle. Então, apresentaremos os resultados do aprisionamento magnético e evidências de compressão.

Por fim, no capítulo V, apresentaremos a discussão e análise sobre o nosso sistema, suas possibilidades, resultados do aprisionamento, evidências de compressão e perspectivas sobre trabalhos futuros envolvendo o mesmo. 


\section{II - Técnicas de Aprisionamento}

Para chegarmos até o regime de condensação de Bose-Einstein (CBE), é necessário que os átomos passem por várias etapas de resfriamento [2], que são as seguintes: partimos de um feixe desacelerado, aprisionamento magneto-óptico, aprisionamento puramente magnético e, por fim, resfriamento evaporativo. Nesse capítulo, descreveremos como ocorre cada etapa do processo de resfriamento, mostrando valores típicos de cada processo.

A CBE depende da relação entre duas grandezas fisicas: densidade e temperatura. A densidade está relacionada com a distância entre os átomos e a temperatura ao comprimento de onda de De Broglie associado a cada átomo. A necessidade de tantos processos de resfriamento vem do fato de termos que otimizar ao máximo a relação entre densidade e temperatura e um bom parâmetro é observarmos a densidade D no espaço de fase, que é dado pela seguinte relação:

$$
\mathrm{D}=\mathrm{n} \lambda_{\mathrm{dB}}{ }^{3}
$$


onde $\mathrm{n}$ é a densidade de átomos e $\lambda_{\mathrm{dB}}$ é o comprimento de onda de De Broglie associado a cada átomo. O sistema sofrerá transição quando $\mathrm{n} \lambda_{\mathrm{dB}}{ }^{3} \cong 2.612$ [1]. Na tabela 1 temos os valores típicos da temperatura $T$, densidade de átomos $\mathrm{n}$ e a densidade no espaço de fase D para cada etapa do processo de resfriamento.

\begin{tabular}{|l|r|r|r|}
\hline & Temperatura & $\begin{array}{c}\text { Densidade } \\
\left(\mathrm{cm}^{-3}\right)\end{array}$ & $\begin{array}{c}\text { Densidade no } \\
\text { Espaço de } \\
\text { Fase }\end{array}$ \\
\hline Forno & $500 \mathrm{k}$ & $10^{14}$ & $10^{-13}$ \\
\hline MOT & $50 \mu \mathrm{K}$ & $10^{11}$ & $10^{-6}$ \\
\hline Resf. Evaporativo & $100 \mathrm{nK}$ & $10^{14}$ & 1 \\
\hline
\end{tabular}

Tabela 1: Valores típicos de temperatura, densidade e densidade no espaço de fase.

A CBE em átomos frios foi obtida, primeiramente, para átomos de metais alcalinos e só posteriormente foi obtida para hidrogênio atômico. Entretanto, muitas das técnicas utilizadas na obtenção da C.B.E. em metais alcalinos foram, primeiramente, desenvolvidas e utilizadas para o hidrogênio atômico, sendo que, durante muito tempo, esse sistema foi a grande promessa. Portanto, por razões históricas, vamos apresentar o sistema utilizando hidrogênio atômico.

\section{II.1 - Hidrogênio "Spin"-Polarizado H个}

Na década de 80 , o sucesso na produção e estabilização de hidrogênio atômico $[9,10,11]$ criou novas perspectivas para o estudo de gases quânticos. Quando o hidrogênio é produzido, a partir da descarga de rádio freqüência em um gás 
molecular de $\mathrm{H}_{2}$, na presença de um forte campo magnético, o estado de "spin" eletrônico é orientado pelo campo, produzindo o chamado sistema "spin" polarizado. Nesta situação, dois átomos que se aproximam não se recombinam para formarem uma molécula. $\mathrm{O}$ gás de hidrogênio polarizado permanece na forma gasosa até mesmo em temperaturas muito próximas do zero absoluto. Isto facilita atingir temperaturas baixas sem a mudança de fase física gás-líquido (ou sólido), presente em quase todos os sistemas físicos conhecidos, criando possibilidades para atingir a temperatura desejada para a CBE. Entretanto, essa idéia não é tão nova, pois em 1959 Hecht [12], também Stwalley e Nosanow [13] em 1976, concluíram que o sistema hidrogênio "spin" polarizado deveria permanecer no estado gasoso próximo do zero absoluto e que seria um ótimo candidato para a obtenção de CBE em gases atômicos pouco interagentes.

Experimentos preliminares com $\mathbf{H} \uparrow$, contidos num recipiente refrigerado, mostraram que a superficie do recipiente era uma fonte indesejável de recombinação do $\mathrm{H} \uparrow$, pois as colisões com as paredes sólidas podem promover a chamada inversão de "spin" ("spin-flip"), proporcionando a recombinação numa colisão subsequente, formando $\mathrm{H}_{2}$ e destruindo a amostra atômica.

Para eliminar os efeitos da superficie no gás de $\mathrm{H} \uparrow$, foi desenvolvida uma armadilha magnética para o $\mathrm{H} \uparrow$, onde os átomos são confinados por campos magnéticos estáticos, não apresentando contato físico com a parede. A primeira demonstração de aprisionamento magnético de átomos neutros foi realizada com $\mathrm{Na}$ (sódio) em 1985 [14]. 


\section{II.1.a - Aprisionamento Magnético}

Para entendermos o princípio do aprisionamento magnético, vamos considerar os estados eletrônicos de um átomo de hidrogênio na presença de um campo magnético estático, como mostrado na figura 1. A combinação do "spin" eletrônico com o "spin" nuclear gera dois possiveis estados para o estado fundamental $1 S_{1 / 2}$ do átomo de hidrogênio: $F=1$ ou $F=0$, onde $F$ representa o "spin" total. Esta distribuição de níveis constitui a chamada estrutura hiperfina do hidrogênio, a qual, na presença de um campo magnético, abre-se em subníveis de acordo com a projeção $\left(m_{F}\right)$ do "spin" total na direção do campo. Há um grupo de estados com energia crescente com o campo magnético e um outro decrescente com este. Átomos nos estados cuja energia cresce com o campo magnético podem ser naturalmente aprisionáveis num mínimo de campo (estados $\left(F=1, m_{F}=1\right)$ e $(F=1$, $\left.\mathrm{m}_{\mathrm{F}}=0\right)$ ). $\mathrm{O}$ princípio da minimização da energia estará sempre fazendo com que haja uma força puxando átomos para a direção do mínimo, transformando esse mínimo num ponto de equilíbrio estável. É desta forma que átomos nestes estados ficam aprisionados no mínimo do campo magnético. Átomos nos estados cuja energia decresce com o campo magnético seriam aprisionados em um ponto máximo de campo. No entanto, as equações de Maxwell permitem produzir mínimos, e não máximos, de campo num espaço livre de corrente, de modo que somente os estados cuja energia aumenta com o campo são aprisionáveis. 


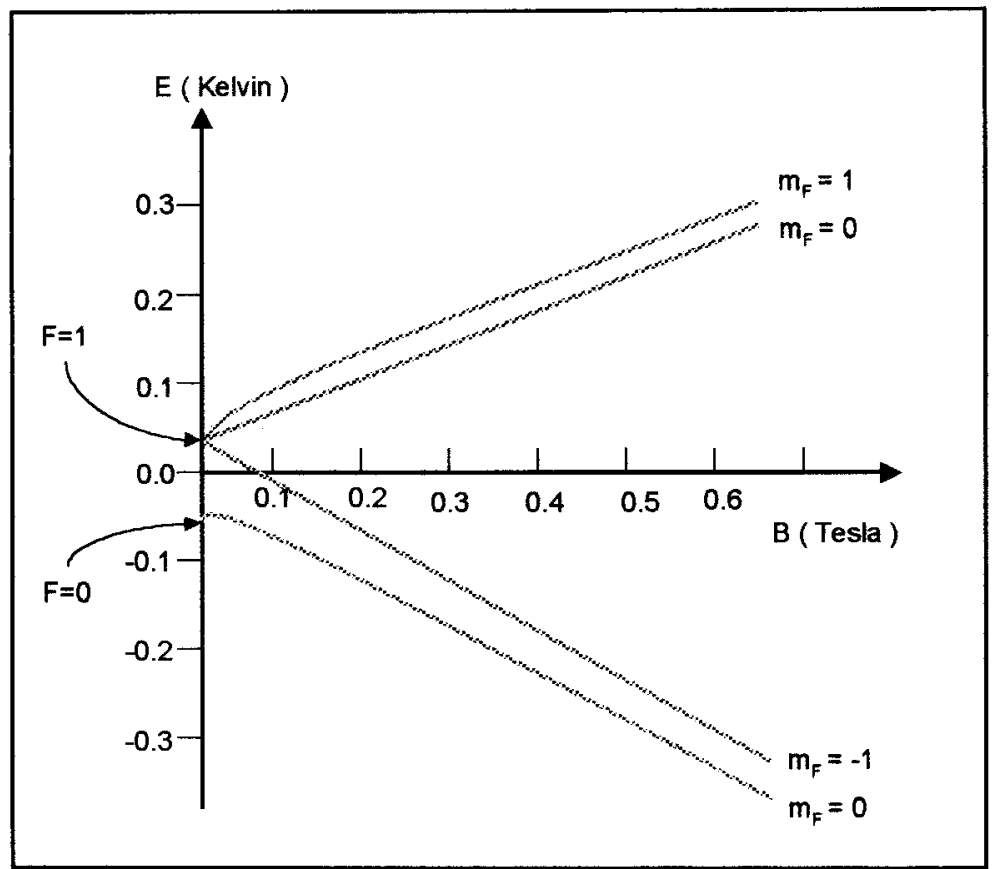

Figura 1: Estados hiperfinos do átomo de hidrogênio na presença de um campo magnético.

O aprisionamento puramente magnético é, pelo menos até o momento, um passo intermediário fundamental para a realização da condensação de Bose-Einstein. A característica mais importante do aprisionamento puramente magnético é o fato deste não necessitar de luz para o confinamento, totalmente livre de fótons e consequentemente livre de todos efeitos provocados por eles em aprisionamentos.

A principal função da armadilha puramente magnética nos experimentos de CBE é acomodar os átomos previamente resfriados e comprimi-los, no caso de metais alcalinos, a fim de termos um resfriamento evaporativo eficiente. A taxa de colisões elásticas após a compressão dos átomos é um dos parâmetros mais importantes do aprisionamento magnético, pois deste valor depende a eficiência do resfriamento evaporativo. Importantes aspectos do aprisionamento magnético de átomos neutros são discutidos nas referências [15-18]. Para uma melhor 
compreensão, tanto qualitativa como quantitativa, sobre aprisionamento magnético de uma maneira geral, vamos fazer uma breve introdução.

As forças magnéticas são grandes quando temos átomos com elétrons não emparelhados, como é o caso dos alcalinos, resultando em um momento magnético $\mu_{\mathrm{m}}$ da ordem do magneton de Bohr. A interação do dipolo magnético com o campo magnético externo é dada por:

$$
\mathrm{U}=-\boldsymbol{\mu}_{\mathrm{m}} \cdot \mathrm{B}=-\left|\boldsymbol{\mu}_{\mathrm{m}}\right|_{\cdot}|\mathrm{B}| . \cos \theta
$$

Classicamente, o ângulo · entre o momento magnético e o campo magnético externo é constante devido ao rápido movimento de precessão de $\mu_{\mathrm{m}}$ ao redor do eixo do campo magnético externo, como descrito na figura 2.

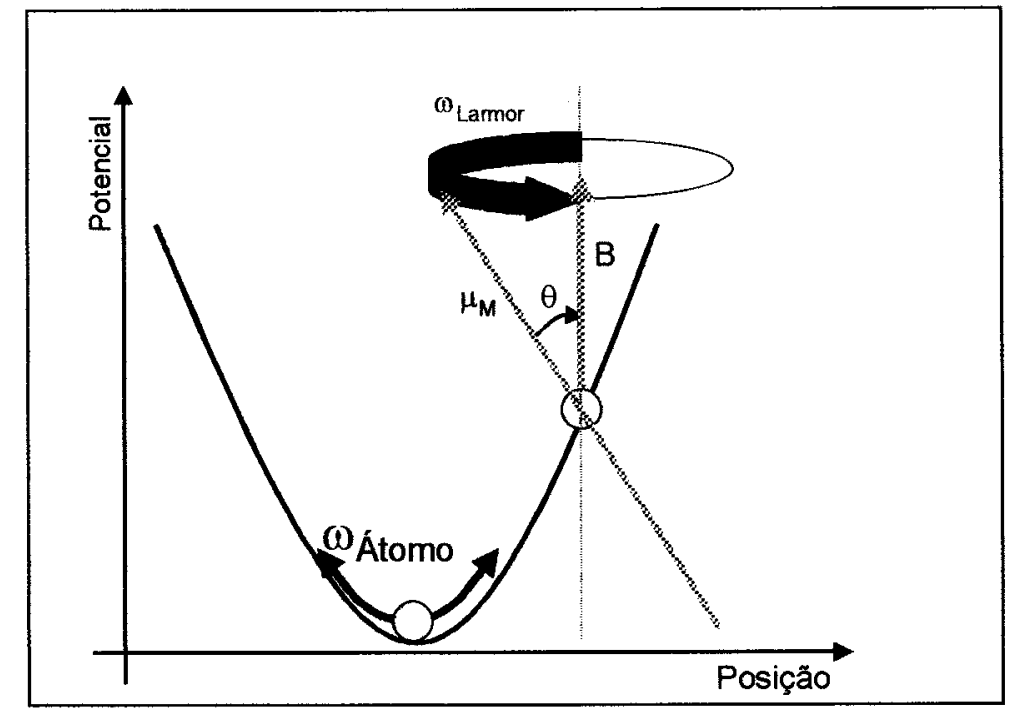

Figura 2: Movimento de precessão de um átomo com momento magnético $\mu_{\mathrm{m}}$ na presença de um campo magnético estático. No centro da figura está a oscilação de um átomo confinado. 
A expressão clássica para a força que atua sobre o átomo é facilmente obtida usando a seguinte relação:

$$
\mathbf{F}_{\mathbf{M}}=-\nabla \mathbf{U}
$$

Quanticamente, as duas equações que governam o nosso sistema para o potencial $U$ e força $F_{M}$ são as seguintes:

$$
\mathrm{U}=-\mu_{\mathrm{s}} \cdot \mathrm{B}=-\left(\mathrm{g}_{\mathrm{s}} \cdot \mu_{\mathrm{B}} / \hbar\right) \mathbf{S} \cdot \mathbf{B}=-\left(\mathrm{g}_{\mathrm{s}} \cdot \mu_{\mathrm{B}} / \hbar\right) \mathrm{M}_{\mathrm{S}} \mathrm{B}
$$

$$
\text { e }
$$

$$
\mathbf{F}_{\mathbf{M}}=-\left(\mathrm{g}_{\mathbf{s}} \cdot \mu_{\mathrm{B}} / \hbar\right) \mathbf{M}_{\mathbf{S}} \nabla \mathbf{B}
$$

onde $\mu_{\mathrm{s}}$ e $\mu_{\mathrm{B}}$ são respectivamente o momento de dipólo do "spin" do elétron e o magneton de Bohr, $\mathrm{M}_{\mathrm{S}}$ é a componente $\mathrm{Z}$ de $\mathrm{S}$, gs é o fator $\mathrm{g}$ de Landé para o "spin" eletrônico. Se o átomo possuir "spin" nuclear I não nulo, devemos substituir o "spin" total F no lugar de S na equação (4) onde F = S + I e o fator g são generalizados da seguinte maneira:

$$
\mathrm{g}_{\mathrm{F}} \cong \mathrm{gS}_{\mathrm{S}}\{[\mathrm{F}(\mathrm{F}+1)+\mathrm{S}(\mathrm{S}+1)-\mathrm{I}(\mathrm{I}+1)] /[2 \mathrm{~F}(\mathrm{~F}+1)]\}
$$


Então, quanticamente, o nosso sistema pode ter os seguintes níveis de energia quando imerso num campo magnético: $\mathrm{E}\left(\mathrm{m}_{\mathrm{F}}\right)=\mathrm{g} \mu_{\mathrm{B}} \mathrm{m}_{\mathrm{F}} \mathrm{B}$. Classicamente, $\theta$ constante é equivalente a mantermos o sistema num estado quântico $\mathrm{m}_{\mathrm{F}}$.

Átomos com $\mathrm{gm}_{\mathrm{F}}>0$ são aprisionáveis em um mínimo local de campo magnético e átomos com $\mathrm{gm}_{\mathrm{F}}<0$ são aprisionáveis em um máximo de campo magnético. Por isso, os estados com $\mathrm{gm}_{\mathrm{F}}>0$ são denominados de estados aprisionáveis em mínimo de campo e os estados com $\mathrm{gm}_{\mathrm{F}}<0$ são denominados de estados aprisionáveis em máximo de campo.

Observando a estrutura do átomo de $\mathrm{H}$, vemos que, no estado fundamental, os estados aprisionáveis em um mínimo de campo magnético são os estados $|1,1\rangle$ e $\mid 1,0>$, onde $\left|F, m_{F}\right\rangle$, e os estados $\mid 1,-1>$ e $\mid 0,0>$ sofrem repulsão de um ponto de mínimo. Quando aprisionamos átomos em um minimo de campo pode haver perdas

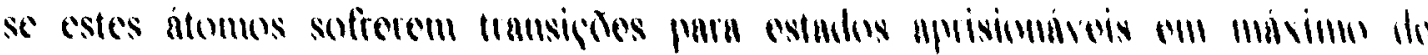
campo. Tais transições podem ser induzidas pelo movimento dos átomos no potencial, pois o átomo verá o campo se movendo, mudando de direção e magnitude Os átomos aprisionados só ficarão estáveis se o momento magnético seguir adiabaticamente o campo magnético. Isto requer que a velocidade com que o campo magnético muda de direção seja muito menor que a freqüência de Larmor do momento magnético, figura 2 . 
Esta condição é violada em regiões de campo magnético com magnitudes muito pequenas. Nessas regiões há perdas de átomos aprisionados devido a transições de "spin" para estados não aprisionáveis. Essas transições são denominadas de "transições majoranas" [19].

No primeiro experimento onde foi observado o aprisionamento magnético de átomos neutros a configuração de campo utilizada foi quadrupolar. Até nos dias de hoje, essa é uma configuração amplamente utilizada, assim teceremos algumas considerações sobre a mesma.

Há basicamente dois tipos de armadilhas magnéticas com campo estático: uma em que o mínimo de campo vale zero e outra em que o mínimo de campo tem um valor finito. Geralmente, armadilhas com mínimo de campo igual a zero são gerados por um potencial linear e caracterizado pelo gradiente de campo da seguinte

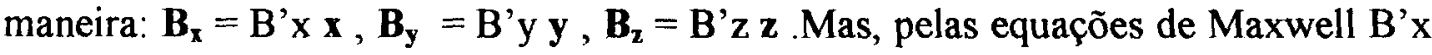
$+B^{\prime} y+B^{\prime} z=0$ e no caso da simetria axial, temos um campo do tipo quadruplo esférico com $B^{\prime} \equiv B^{\prime} x=B^{\prime} y=-B^{\prime} z / 2$. Este tipo de campo é obtido utilizando um par de bobinas na configuração anti-Helmoltz. Nesta configuração de bobinas o campo é zero no centro geométrico do sistema e cresce linearmente em todas as direções, fazendo com que este ponto seja um mínimo absoluto aprisionando átomos. Este poço, entretanto, é muito raso ( da ordem de décimos de Kelvin), o que implica que os átomos devem ser previamente resfriados, antes do aprisionamento magnético ser iniciado. Mas a dinâmica deste sistema é extremamente complexa. Há grandes 
perdas de densidade e nos números de átomos aprisionados devido à relaxação dipolar e a colisões de três corpos. Por isso, os vários trabalhos realizados com $\mathrm{H} \uparrow$ só atingiram o regime necessário para a observação da CBE. Algum tempo depois da observação desta em metais alcalinos. Porém, através deste experimento, introduziuse uma poderosa técnica de resfriamento atômico: o resfriamento evaporativo, que foi um passo de importância fundamental para a observação da C.B.E.

\section{II.1.b - Resfriamento evaporativo}

O resfriamento evaporativo $[20,21]$ baseia-se no fato de que se removermos as partículas mais energéticas de um sistema em equilibrio, o restabelecimento do equilíbrio resfria o sistema como um todo. Imagine um gás contido em um recipiente obedecendo uma distribuição de velocidade do tipo Maxwell-Boltzman, como mostrada na figura 3a. Diminuindo a barreira de potencial, figura 4, vamos remover os átomos com velocidades acima de $v_{c}$, produzindo uma distribuição truncada, como mostrada na figura $3 \mathrm{~b}$. Esta distribuição truncada vai retornar a uma distribuição de Maxwell-Boltzman através da retermalização de seus constituintes. Para que isso ocorra, parte da distribuição que ficou deverá repor as classes de velocidades faltantes. Isto ocorrerá às custas do sistema se resfriar um pouco, de modo que a nova distribuição tenha não somente um número menor de partículas, mas também uma temperatura mais baixa, como na figura $3 \mathrm{c}$. O processo de resfriamento evaporativo é importante porque permite atingir temperaturas extremamente baixas, centenas de nanokelvin, claro que às custas de uma certa 
fração de partículas, aumentando também consideravelmente a densidade do espaço de fase

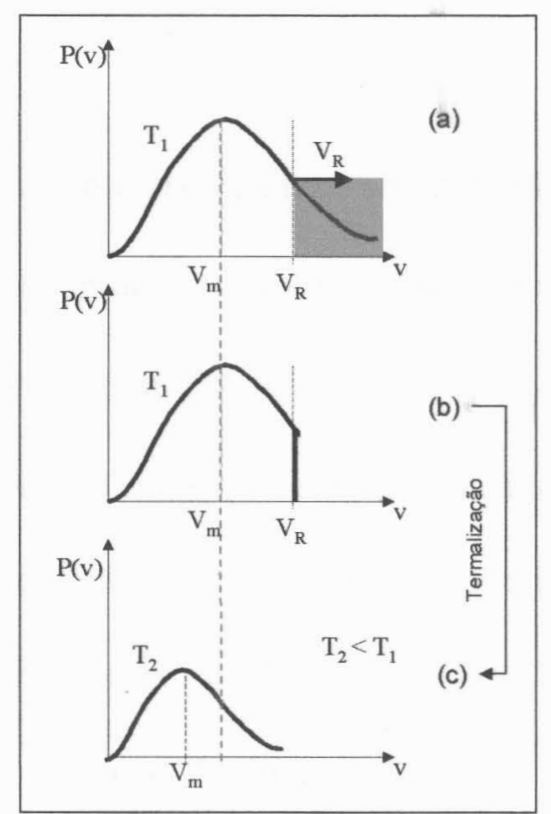

Figura 3: Processo de resfriamento evaporativo em uma distribuição de velocidades: (a) distribuição a uma temperatura $T_{1}$, (b) distribuição truncada e (c) nova distribuição após a retermalização a uma temperatura $T_{2}, T_{2}<T_{1}$.

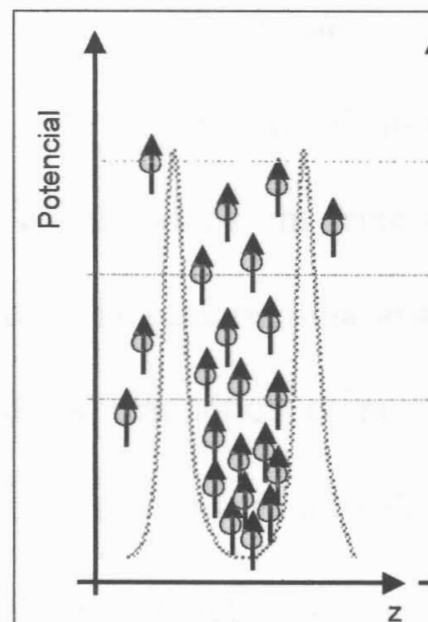

(a)

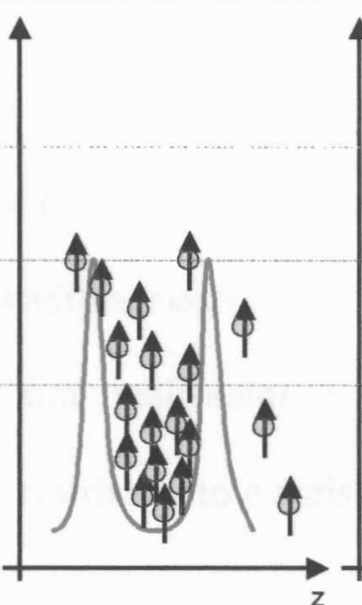

(b)

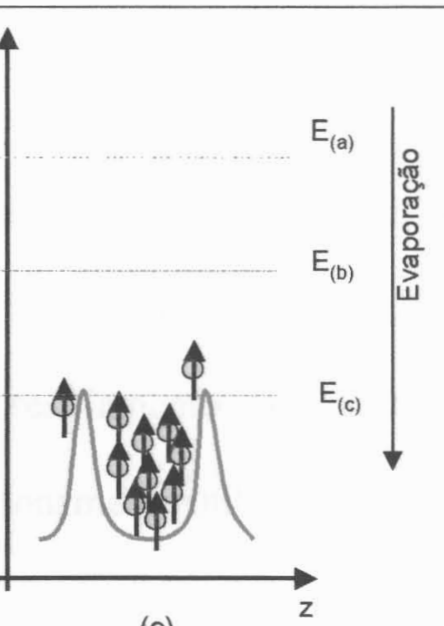

Figura 4: Resfriamento evaporativo de átomos aprisionados magneticamente. Abaixando o potencial vamos eliminando os átomos mais quentes. 


\section{II.2 - Resfriamento e Aprisionamento de Metais Alcalinos}

Os trabalhos em metais alcalinos são baseados nos experimentos com sistema $\mathrm{H} \uparrow$ (hidrogênio "spin" polarizado) em vários aspectos. O resfriamento evaporativo foi desenvolvido, primeiramente, para o $\mathrm{H} \uparrow$ e posteriormente utilizado em metais alcalinos, inclusive sendo mais eficiente nos alcalinos. Muitos aspectos da CBE em potenciais não homogêneos, bem como as teorias sobre processos de colisões desenvolvidas nos anos 80 para o hidrogênio [22], podem ser diretamente aplicadas para sistemas com alcalinos. As idéias e técnicas utilizadas no sistema hidrogênio "spin" polarizado são as mesmas que serão utilizadas para sistemas com gases de alcalinos, entretanto, a sua implementação experimental é sensivelmente diferente. Para o sistema $\mathrm{H} \uparrow$, já carregamos a armadilha magnética após a quebra da molécula de $\mathrm{H}_{2}$. Para os metais alcalinos, é necessário um pré-resfriamento que, em nosso caso, é resfriarmos um feixe atômico, pois necessitamos de um grande números de átomos. Carregamos uma armadilha magnéto-óptica e só depois iremos carregar a armadilha magnética e, por fim, realizamos o resfriamento evaporativo. Então, apresentaremos as técnicas de resfriamento e aprisionamento utilizadas para sistemas com átomos de metais alcalinos. 


\section{II.2.a - Feixe Atômico}

A produção de feixes atômicos resfriados utilizando-se pressão de radiação ressonante tem sido amplamente realizada nas duas últimas décadas. Além disso, há inúmeras técnicas diferentes. Em nosso caso, utilizamos a técnica de ajuste Zeeman, primeiramente demonstrada por Phillips et al. [23].

A idéia básica do resfriamento de um feixe atômico é a utilização do fato de que os fótons carregam momento e, então, utilizamos um feixe de luz para fazer pressão sobre os átomos do feixe. Vamos imaginar um átomo, com dois estados, propagando-se com uma determinada velocidade v. Contra propagante a este feixe de átomos vamos aplicar um feixe de luz "laser", monocromático e com a freqüência ligeiramente deslocada para o vermelho da transição. $\mathrm{O}$ átomo irá absorver um fóton, sofrerá uma transição para o estado excitado e irá sofrer um recuo devido ao momento carregado pelo fóton. Após algum tempo, o átomo voltará para o estado fundamental emitindo um fóton, em uma direção aleatória. Depois de muitas absorções e emissões, na média, o átomo sofrerá uma força somente no sentido contrário à direção em que se move, conforme mostrado na figura 5. A força sofrida pelos átomos, ao longo de sua trajetória contrária ao feixe de luz "laser", será uma força do tipo viscosa, -bv, calculada por Cook [24]. Com a redução na velocidade dos átomos, rapidamente eles estarão fora de ressonância com o feixe de desaceleração, devido ao efeito Doppler. Então, para que os átomos estejam sempre 
em ressonância com o feixe desacelerador aplicamos um campo magnético para que o efeito Zeeman compense o efeito Doppler, esta técnica é conhecida como ajuste Zeeman. No caso de um feixe de átomos de sódio, a velocidade final dos átomos no feixe é em torno de $30 \mathrm{~m} / \mathrm{s}$, que corresponde a aproximadamente $1 \mathrm{~K}$, o suficiente para serem capturados em uma armadilha magneto-óptica. Para fazermos esta transferência do feixe para a armadilha utilizamos a técnica "Dark slowing beam", que inclusive, foi desenvolvida pelo nosso grupo [25 ].

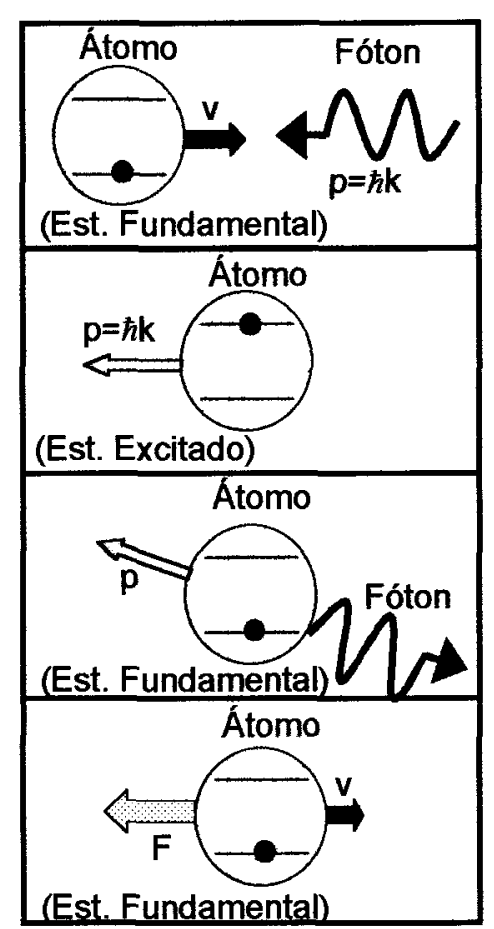

Figura 5: Átomos sendo desacelerados por um feixe de "laser" contra propagante.

\section{II.2.b - Melaço Óptico}

A idéia de melaço óptico [26] é uma extensão do princípio utilizado para resfriar feixes atômicos. Se, ao invés de um feixe sobre uma amostra, incidirmos seis 
feixes contra propagantes produziremos uma amostra resfriada. Nessa configuração a temperatura das amostras seria em torno de microKelvin ou menos. A produção do melaço óptico será necessária para a transferência da amostra resfriada do MOT para a armadilha magnética.

\section{II.2.c - Aprisionamento Magneto-óptico MOT}

A pressão de radiação exercida pelo feixe laser sobre os átomos do feixe atômico só os resfria, não os confina, pois é uma força do tipo viscosa. Para que tenhamos uma força que confine o átomo em uma determinada região do espaço, é necessária uma força restauradora dependente da posição. Isto é feito utilizando-se um campo magnético que varia linearmente no espaço. Devido à estrutura interna do átomo, um campo magnético não homogêneo pode criar uma regra de seleção para transições radiativas dependentes da posição em que o átomo se encontre, da seguinte maneira:

Considere um átomo hipotético cujo estado fundamental apresenta spin $S=0$ $\left(m_{S}=0\right)$ e o estado excitado apresenta $S=1\left(m_{S}=-1,0,+1\right)$. Colocando este átomo hipotético em um campo magnético fraco e do tipo $\mathrm{B}(\mathrm{z})=\mathrm{bz}$ (cresce linearmente com a posição), a abertura Zeeman das energias será dada por $\Delta E=\mu \mathrm{m}_{\mathrm{S}} B=\mu b \mathrm{~m}_{\mathrm{s}} \mathrm{z}$, como mostrado na figura 6(a). Agora vamos iluminar esses átomos com dois feixes de luz laser contra propagantes com polarizações circulares opostas, $\sigma^{-}$na direção contrária a $z$ e $\sigma^{+}$na direção de $z$. Serão ainda sintonizados para o vermelho para manter a 
presença da força viscosa discutida anteriormente. Nessa nova situação, a força de radiação exercida sobre o átomo é dependente da posição e o mecanismo para que isso ocorra é o seguinte: quando o átomo desloca-se para a direita a transição eletrônica $S=0\left(m_{S}=0\right) \rightarrow S=1\left(m_{S}=-1\right)$ é a que fica mais próxima da ressonância com o laser aplicado da direita para a esquerda. Como este feixe de luz tem polarização circular levógira, pelas regras de seleção para transições atômicas na aproximação de dipolo elétrico, este é o feixe que irá interagir mais fortemente com o átomo, exercendo uma força da direita para a esquerda que procura restaurar a posição de equilíbrio, $Z=0$. Quando o átomo desloca-se para a esquerda, o mecanismo de interação é o mesmo, só que agora favorece a transição eletrônica $S=0$ $\left(m_{S}=0\right) \rightarrow S=1\left(m_{S}=+1\right)$, resultando em uma força da esquerda para a direita que procura restaurar a posição de equilíbrio, $Z=0$, [27].

O resultado global da força dissipativa mais a força restauradora é que o átomo fica sujeito a uma força do tipo oscilador harmônico amortecido. Se, ao invés de uma dimensão, os feixes de luz e o campo magnético atuarem nas três dimensões $(x, y, z)$, a força resultante pode ser generalizada produzindo um átomo confinado no espaço. Para três dimensões, o campo será gerado por um par de bobinas na configuração anti-Helmoltz e as polarizações deverão estar de acordo com a figura 6(b). Para átomos de sódio, a transição utilizada para o aprisionamento magnetoóptico está apresentada na figura 7. Mas, neste sistema, temos algumas limitações: a temperatura é limitada pela emissão espontânea, a densidade é limitada pelo espalhamento de fótons e também pelas perdas devido a colisões no estado excitado. 
Em geral, nas armadilhas magneto-ópticas conseguimos aprisionar $10^{8}$ átomos com densidades de aproximadamente $10^{10}$ átomos $/ \mathrm{cm}^{3}$ a uma temperatura da ordem de $200 \mu \mathrm{K}$.

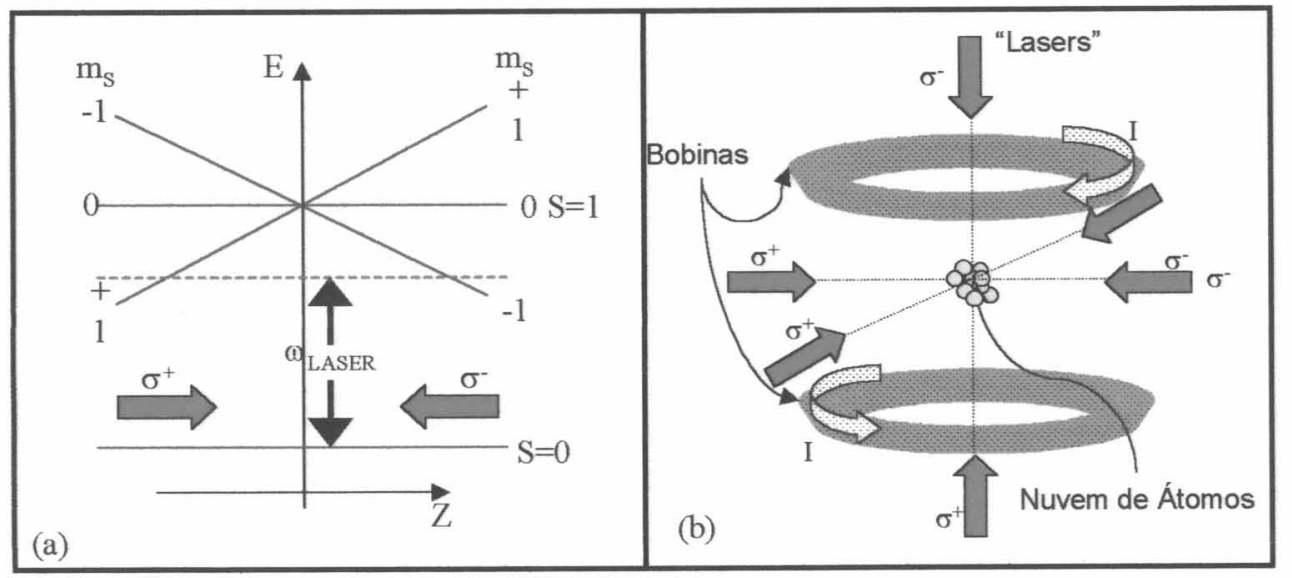

Figura 6: (a) Abertura Zeeman das energias, (b) Bobinas na configuração para gerar campo linear e as polarizações adequadas para construção do MOT.

Além do feixe de aprisionamento temos um outro feixe em outra freqüência, denominado de feixe de rebombeio e este é necessário para que sempre tenhamos átomos no estado aprisionável.

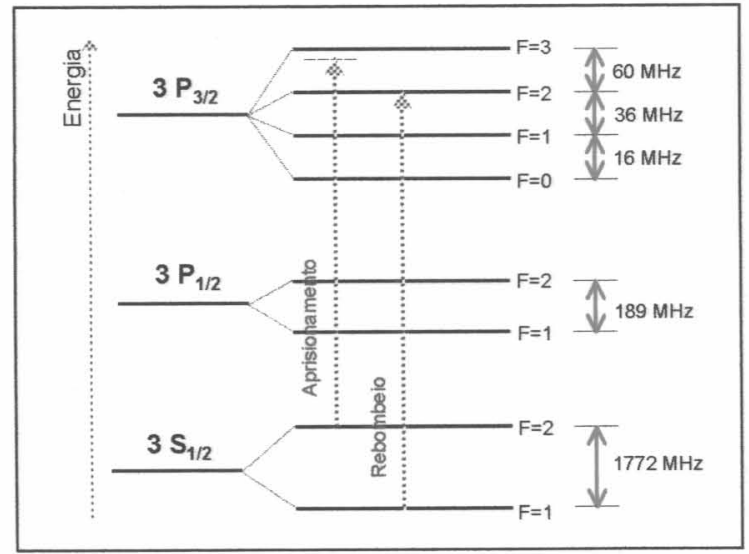

Figura 7: Estrutura hiperfina do átomo de Sódio. 
Uma maneira alternativa para minimizar as limitações citadas acima é utilizarmos o "Dark MOT" [28]. O "Dark MOT" consiste de um MOT com a diferença que fazemos uma sombra no centro do "Spot" do feixe de rebombeio, como pode ser observado na figura 8. Dessa maneira, diminuímos as limitações.

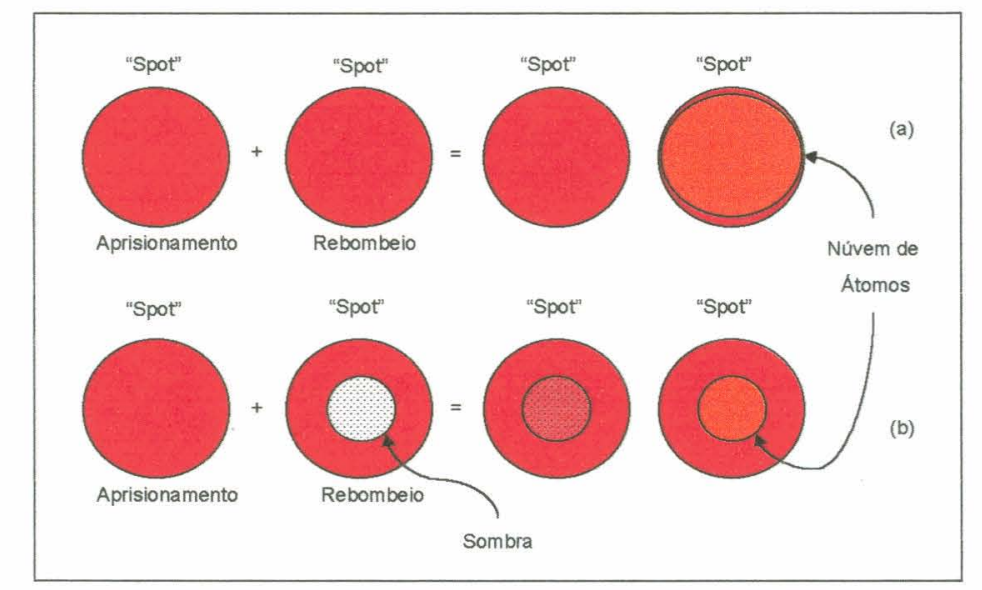

Figura 8: (a) Representação do "spot" do feixe "laser" para o MOT comum, (b) Configuração do "spot" para a obtenção do "dark MOT".

devido à absorção de luz e perdas devido a colisões induzidas por luz "laser". Pois quando o átomo estiver na sombra do rebombeio ele irá permanecer em um estado não aprisionável $\left(3 \mathrm{~S}_{1 / 2}, \mathrm{~F}=1\right)$. Evitando assim a ocorrência de processos que dependam do estado excitado. No MOT, a temperatura da amostra fica limitada pela emissão espontânea e a densidade fica limitada por perdas causadas pelas colisões no estado excitado. Com esta alternativa podemos conseguir quase duas ordens de grandeza a mais na densidade. 


\section{II.2.d - Configurações de Aprisionamentos Magnéticos}

Nas armadilhas magnéticas, a perda de átomos próximos de $\mathrm{B}=0$ devido a transições majoranas é muito grande. Então, para tampar esse buraco têm sido utilizadas várias técnicas diferentes e de grande criatividade, utilizando campos magnéticos oscilantes, “TOP trap" [6], ou utilizando a pressão de radiação para tirar os átomos da região de perdas, "Optical Plug" [8].

Uma outra maneira de evitar as perdas devido às transições Majoranas é utilizar uma configuração de campo magnético estático em que o mínimo de campo seja um valor não nulo, $\mathrm{B}_{0}$, que seja suficientemente grande para minimizar as perdas. Como exemplo, podemos citar algumas configurações: Ioffe-Pritchard [16], folha de trevo [29], "Baseball" [30], "Ying-Yang" [31], bobina tripla [32] e muitas outras.

\section{II.2.d.1 - Configuração Ioffe-Pritchard (IP)}

A configuração Ioffe-Pritchard possui este nome por ter sido primeiramente proposta e demonstrada no aprisionamento de átomos frios por Pritchard [33]. Mas, uma configuração similar já havia sido proposta e testada muito antes por Ioffe, porém, era utilizada para o confinamento de plasma [34]. Na configuração IP, o campo magnético gera um potencial do tipo oscilador harmônico que, na região de 
mínimo de campo, possui um valor de fundo ("bias"), $\mathrm{B}_{0}$, não nulo. Ao longo do eixo $z$ temos um campo axial do tipo: $B_{Z}=B_{0}+B^{\prime \prime} z^{2} / 2$. Já sua componente possui um comportamento linear $\mathbf{B}_{\mathbf{X}}=\mathbf{B}^{\prime} \mathbf{x}$. Aplicando-se as equações de Maxwell, supondo simetria axial, teremos a seguinte configuração de campo para o sistema IP:

$$
B=B_{0}\left(\begin{array}{l}
0 \\
0 \\
1
\end{array}\right)+B^{\prime}\left(\begin{array}{c}
x \\
-y \\
0
\end{array}\right)+B^{\prime \prime} / 2\left(\begin{array}{c}
-x z \\
-y z \\
z^{2}-1 / 2\left(x^{2}+y^{2}\right)
\end{array}\right)
$$

O sistema IP possui dois regimes de confinamento dependendo da temperatura da amostra a ser aprisionada. Para temperaturas: $\left(K_{B} T<\mu_{m} B_{0}\right)$ o potencial de confinamento o qual a amostra estará sujeita será um potencial do tipo oscilador harmônico anisotrópico nas três direções. No caso onde a temperatura: $\left(\mathrm{K}_{\mathrm{B}} \mathrm{T}<\mu_{\mathrm{m}} \mathrm{B}_{0}\right)$ o potencial será predominantemente linear ao longo da direção radial $\left(U_{\rho}=\mu_{m} B ' \rho\right)$ e harmônico na direção axial $\left(U_{Z}=\mu_{m} B " z^{2} / 2\right)$. Uma outra aproximação interessante de observarmos é como será o potencial de confinamento quando o volume das nuvens atômicas for muito pequeno, como é o caso de todos os condensados. Neste caso, o potencial é aproximadamente um oscilador harmônico anisotrópico, com:

$$
\begin{aligned}
& \mathrm{U} \cong \mu_{\mathrm{m}}\left(\mathrm{B}^{\prime \prime}{ }_{\text {Radial }} \rho^{2}+\mathrm{B} " \mathrm{z}^{2}\right) / 2 \\
& \mathrm{~B}{ }_{\text {Radial }}=\left(\mathrm{B}^{\prime 2} / \mathrm{B}_{0}-\mathrm{B} " / 2\right)
\end{aligned}
$$


A partir de um certo deslocamento axial o confinamento radial desaparece. Isto ocorre porque a componente radial da curvatura, -B"xz/2, interfere destrutivamente com o gradiente radial B'. Partindo da equação (9) podemos encontrar o ponto de instabilidade, dado por:

$$
\mathrm{Z}_{\text {inst }}= \pm\left(\mathrm{B}^{\prime} / \mathrm{B}^{\prime \prime}-\mathrm{B}_{0} / 2 \mathrm{~B}^{\prime}\right)
$$

Quando $\mathrm{B}{ }_{\text {Radial }}<0$ a instabilidade estará na origem. A existência desses pontos de instabilidade requer uma atenção muito especial quando formos tratar a transferência do MOT para a armadilha magnética. A configuração IP é usada em muitos experimentos de $\mathrm{CBE}$ devido à sua facilidade na implementação. $\mathrm{O}$ sistema IP consiste de duas bobinas de curvatura (ou "bias") e quatro barras de Ioffe, como mostrado na figura 9. Outras configurações IP podem ser feitas utilizando-se magnetos permanentes.

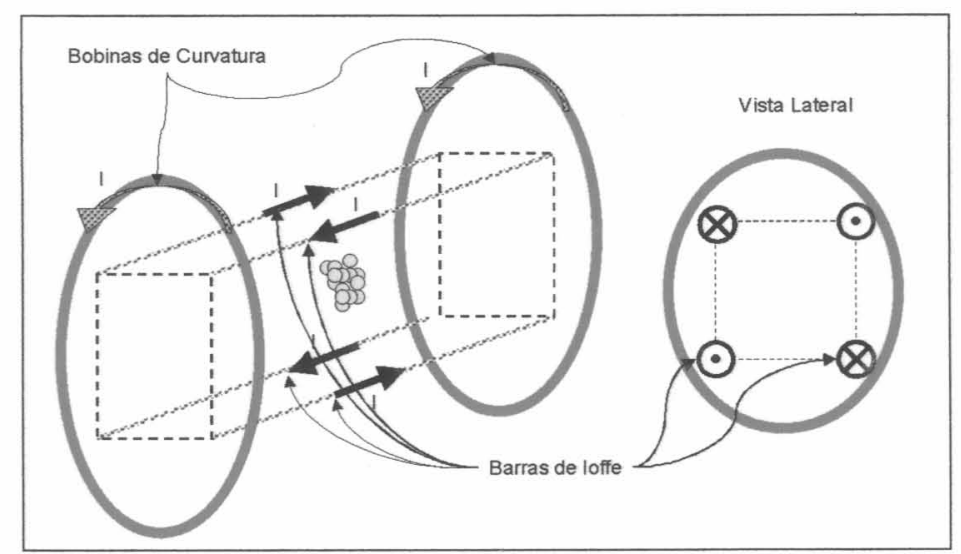

Figura 9: Sistema de bobinas na configuração Ioffe-Pritchard. 
As barras de Ioffe geram o gradiente de campo radial B', as bobinas de curvatura produzem o campo de fundo, $\mathrm{B}_{0}$, e o termo de curvatura B". A maior parte do campo de fundo é geralmente cancelada por um par de bobinas de compressão (ou "anti-bias"). Pela equação (11), quando reduzimos o valor de $\mathrm{B}_{0}$ aumentamos o confinamento radial do sistema, pois $\mathrm{B}_{0}$ só é necessário para reduzir a transição Majorana e valores de $B_{0}$ da ordem de 1 gauss já são o suficiente para evitarmos perdas consideráveis. Com o sistema de bobinas de curvatura e compressão pode-se gerar campos da ordem de centenas de gauss. $O$ cancelamento pode ser cuidadosamente controlado, moldando o potencial de acordo com as nossas necessidades.

O aprisionamento magnético com as bobinas de curvatura e as barras de Ioffe produzem um potencial de confinamento muito estreito [35] e isso é muito importante para o próximo passo do resfriamento, que é o resfriamento evaporativo. Uma das grandes desvantagens deste sistema é a dificuldade no acesso óptico ao centro da câmara onde estarão os átomos aprisionados. Para evitarmos este problema vamos aumentar o tamanho das bobinas de curvatura e substituir as quatros barras de Ioffe por quatro bobinas ao redor de cada bobina de curvatura, figura 10. Este novo sistema é denominado de folha de trevo.

A configuração folha de trevo é qualitativamente idêntica ao sistema IP, com a única diferença de que, agora, são as oito bobinas de folha de trevo que irão gerar o gradiente radial de campo, anteriormente gerados pelas quatros barras de Ioffe. No sistema folha de trevo temos $360^{\circ}$ de acesso óptico no plano x-y. Mas, a grande vantagem do sistema folha de trevo e do sistema IP em relação aos outros citados 
anteriormente, é que este sistema permite o controle independente de B' e B" e do confinamento radial que pode ser alterado variando o valor do campo de fundo.

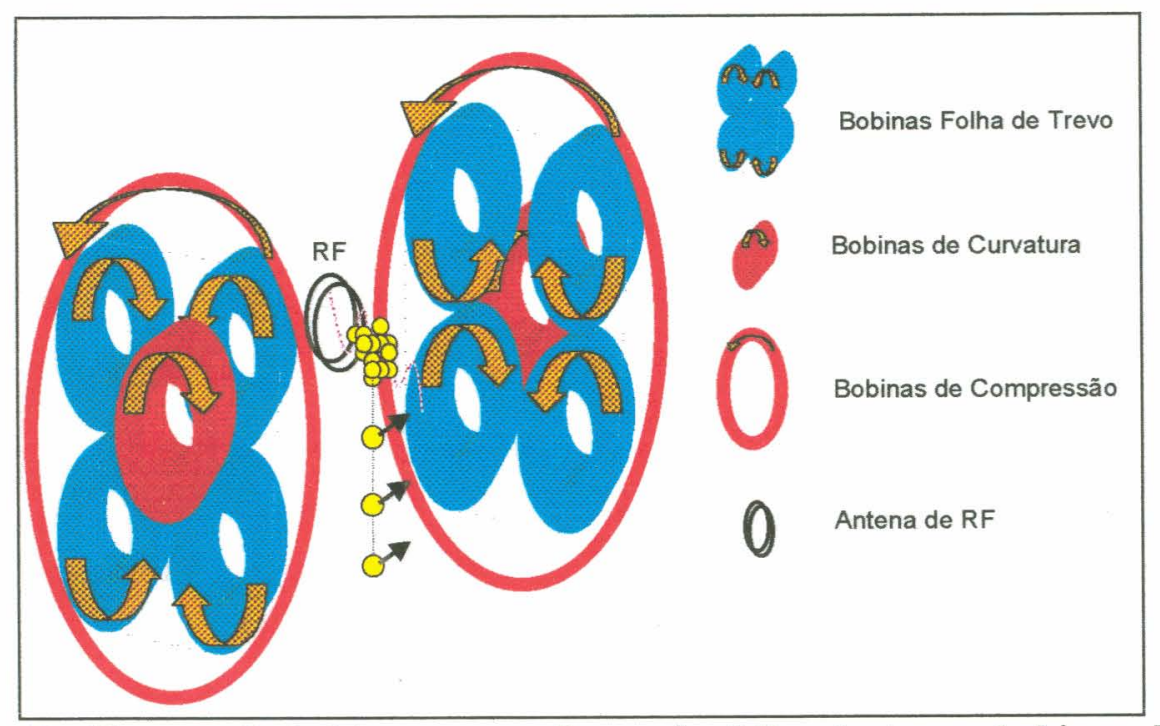

Figura 10: Sistema de bobinas na configuração folha de trevo, bobinas de curva e bobinas de compressão.

O sistema pelo qual optamos foi à configuração folha de trevo por reunir todas as vantagens citadas anteriormente e algumas outras que ficarão mais evidentes quando apresentarmos, no próximo capítulo, o esquema da montagem do nosso experimento.

\section{II.2.d.2 - Compressão Adiabática}

A realização do resfriamento evaporativo [8] só será possível se o tempo de retermalização do sistema for bem menor comparado com o tempo de vida da armadilha magnética. A retermalização do sistema ocorre via colisão elástica. Então, aumentando a taxa de colisão diminuiremos o tempo de retermalização. Portanto, 
após a transferência dos átomos do MOT para a armadilha magnética, comprimimos adiabaticamente o potencial de confinamento para aumentarmos a taxa de colisão. Comprimir adiabaticamente significa que não haverá alteração da densidade do espaço de fase durante a compressão. Em geral, a compressão adiabática aumenta a velocidade de colisão elástica por um fator de 20.

Uma pergunta que poderia ser feita é a seguinte: se vamos ter que fazer a compressão, por que já não transferimos os átomos do MOT diretamente para um potencial confinado? Não fazemos isto por dois motivos. Primeiro, o potencial da armadilha magnética deve ser parecido com o do MOT, pois, caso não seja poderemos esquentar os átomos durante a transferência. Segundo, durante a transferência devemos ter um alto valor de campo de fundo, $\mathrm{B}_{0}$, pois, quanto maior $\mathrm{o}$ valor de $\mathrm{B}_{0}$, mais afastado do centro estará a região de instabilidade do potencial. Alto valor de $\mathrm{B}_{0}$ implica em baixo confinamento para o sistema IP, figura 11 .

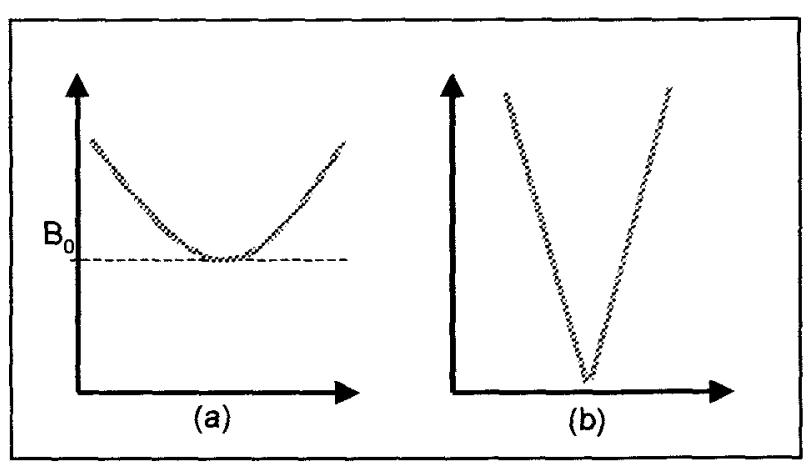

Figura 11: (a) Potencial com um alto valor de $B_{0}$, potencial pouco confinante, (b) potencial comprimido, baixo valor de $B_{0}$. 


\section{II.2.e - Resfriamento Evaporativo}

No caso de metais alcalinos, o processo de remoção $[20,21,36]$ dos átomos mais quentes da distribuição é ligeiramente diferente do sistema de hidrogênio atômico. Para removermos os átomos, alcalinos, mais energéticos da distribuição utilizamos rádio-frequêencia, rf. Com o fóton de rf promovemos uma transição para um estado de "spin" não aprisionável em um mínimo de campo. Temos também a vantagem de induzirmos essa transição nos átomos mais quentes. Podemos visualizar esse processo de várias maneiras diferentes, uma delas é observarmos a figura 12 .

No aprisionamento magnético, os átomos estão sujeitos a um determinado potencial. Com a rf vamos criar um novo potencial e, varrendo podemos abaixar a energia potencial eliminando, assim, os átomos mais quentes. Uma outra maneira de visualizarmos tal processo é observarmos a abertura Zeeman dos níveis do sódio, figura 13. Com a rf induzimos a transição do estado $\mid 1,-1>$ para o estado $\mid 1,0>$, que é um estado indiferente ao campo, e ainda induzimos estes átomos no estado $\mid 1,0>$ para o estado $\mid 0,+1>$ que é um estado que sofrerá repulsão.

Quanto mais quentes os átomos, maior será o campo magnético B que estarão sujeitos e maior é a abertura Zeeman destes níveis. Então, se varrermos a rádiofreqüência de altas freqüências até baixas freqüências iremos induzir a transição partindo dos átomos mais quentes até os mais frios. Em geral, a varredura de rádiofreqüência vai de $20 \mathrm{MHz}$ até $0,7 \mathrm{MHz}$ em alguns segundos. 
33

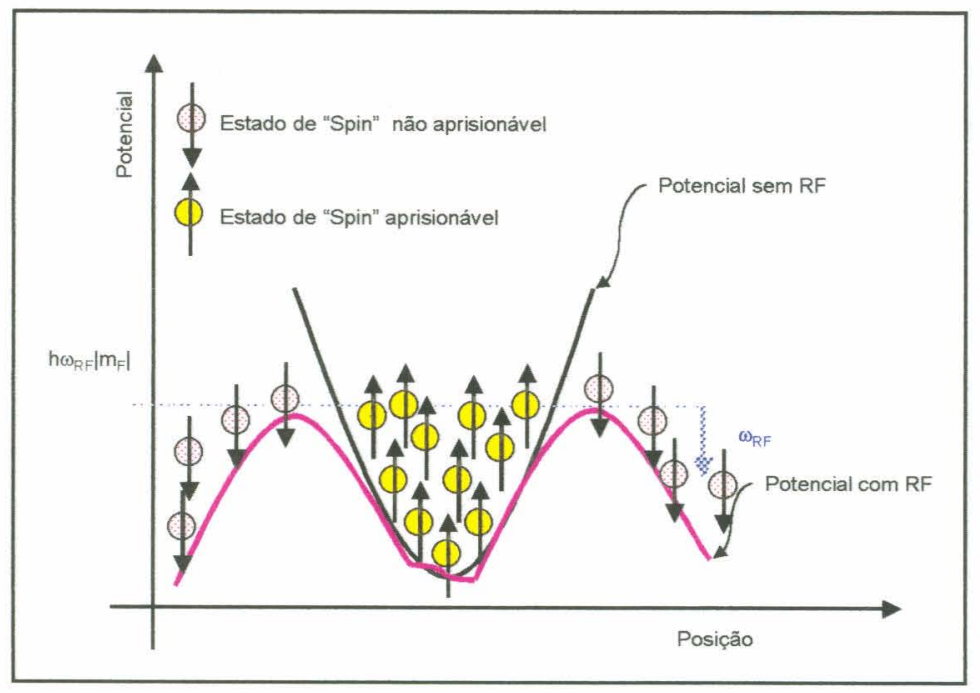

Figura 12: Resfriamento evaporativo em metais alcalinos, no caso sódio, induzido por rádio-freqüência.

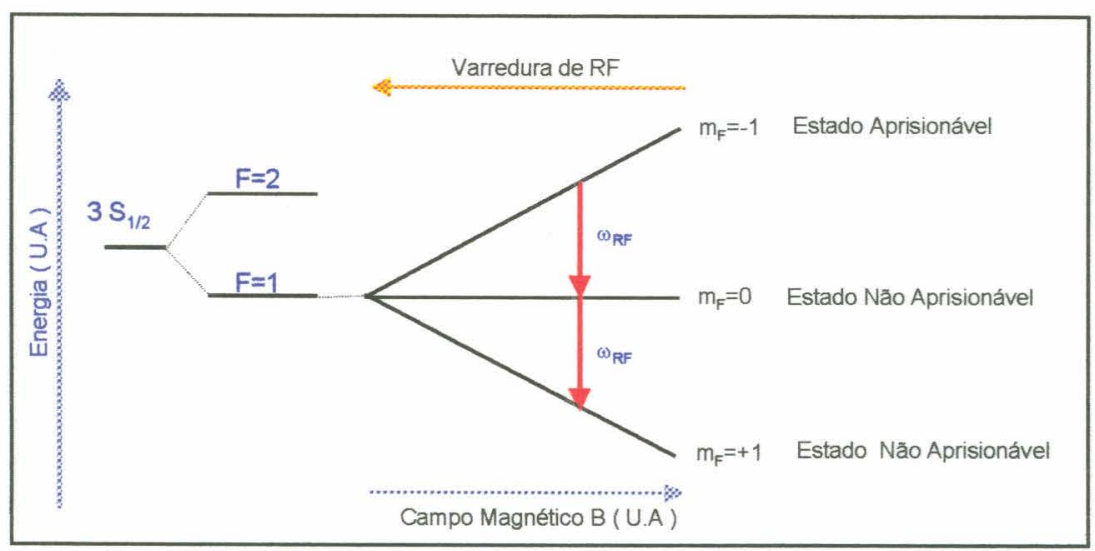

Figura 13: Abertura Zeeman das linhas do átomo de sódio e as transições para a realização do resfriamento evaporativo. 


\section{III - Montagem Experimental}

Neste capítulo, vamos descrever a montagem experimental do sistema, tanto mecânico quanto elétrico. Apresentaremos as simulações dos campos assim como um breve comentário sobre o programa para os cálculos. Mas, antes de tudo, devemos compreender a necessidade desta configuração. Temos dois motivos: precisamos de determinada configuração de corrente para gerar os campos necessários e a seqüência temporal em que estes eventos deverão ocorrer é muito importante. Ao longo do capítulo descreveremos estes motivos.

\section{III.1 - Seqüência Temporal do Experimento}

Muito mais importante que a realização individual de cada etapa apresentada até o momento, é a seqüência temporal destes eventos. O processo de desaceleração do feixe é feito simultaneamente com o carregamento do MOT, então, temporalmente vamos considerá-los como um único evento.

Depois de um MOT otimizado devemos transferir os átomos do MOT para a armadilha magnética e isto não é um processo tão simples como parece. Neste 
processo de transferência, devemos lembrar de quatro fatores importantes. Primeiro, uma característica intrínseca do sistema é que iremos transferir, no máximo, 1/3 dos átomos do MOT para a armadilha magnética, pois, dos átomos do MOT no estado fundamental $\left(3 \mathrm{~S}_{1 / 2}, \mathrm{~F}=1\right)$ só um terço estará no estado aprisionável num mínimo de campo $\left(3 \mathrm{~S}_{1 / 2}, \mathrm{~F}=1, \mathrm{~m}_{\mathrm{F}}=-1\right)$. Segundo, os potenciais(do MOT e da armadilha magnética) deverão estar centrados, pois caso não estejam, os átomos esquentarão após a transferência fazendo com que haja perdas na eficiência da transferência que já está limitada pelo item anterior. Terceiro, é um fator de caráter temporal, assim que desligarmos o MOT a nuvem de átomos irá se expandir e se demorarmos muito para ligar o potencial da armadilha magnética não haverá átomos a serem capturados. Para evitarmos tal problema fazemos uma fase intermediária de melaço óptico.

Quarto, este é um fator devido à configuração Ioffe-Pritchard, $\mathrm{z}_{\text {linst }} \propto \mathrm{B}_{0}{ }^{1 / 2} \propto$ B', então, para evitarmos perdas devido aos átomos estarem próximos de regiões de instabilidade do potencial, devemos ter um tempo de chaveamento das correntes muito rápido, e também um alto valor de corrente para que tenhamos altos valores de campo e gradiente

Após os átomos terem sido transferidos para a armadilha magnética é realizada a compressão adiabática e em seguida, a radio freqüência será irradiada para a realização do resfriamento evaporativo. Para fazermos a imagem dos átomos da armadilha magnética, desligamos os campos e damos um pulso com o feixe de aprisionamento e o de rebombeio e observamos a fluorescência na câmera $\mathrm{CCD}$. Então, para termos uma melhor compreensão de toda a seqüência temporal, podemos observar a figura 14. 


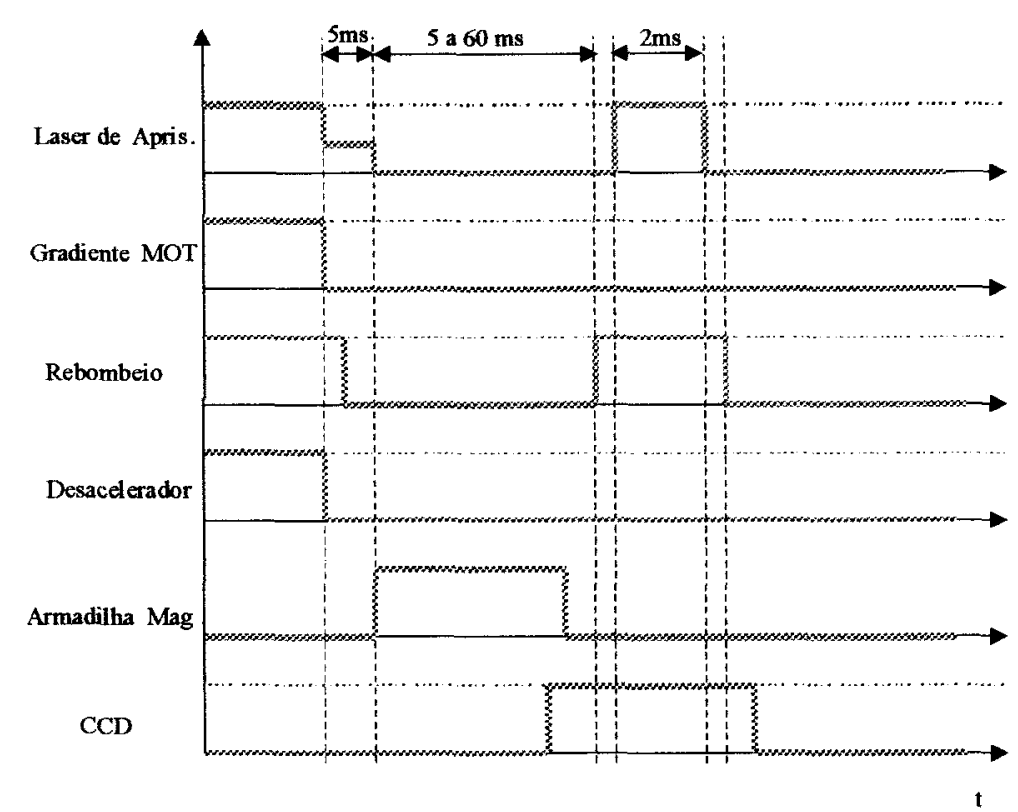

Figura 14: Seqüência temporal para cada etapa do processo.

\section{III.2 - Simulação dos Campos}

Na construção das bobinas, devemos conciliar dois aspectos importantes. Primeiro, é encontrar a melhor configuração de bobinas para gerar os campos necessários. Segundo, adaptar essa configuração ao sistema que temos, tanto mecânico quanto elétrico. No item II.2.d.1, discutimos a respeito da configuração do sistema folha de trevo, optado por nós. No sistema, as bobinas de curvatura geram o campo de fundo, $\mathrm{B}_{0}$, e o termo de curvatura, B". As bobinas de folha de trevo são responsáveis pelo gradiente radial. Estes são os parâmetros importantes para o aprisionamento. Para simularmos os campos necessários utilizamos a referência [16], 
onde há uma extensa discussão sobre configurações de campos magnéticos utilizados para o aprisionamento de átomos neutros. Além disso, apresenta uma breve discussão sobre métodos aproximativos para o cálculo numérico de tais campos. Implementamos um programa, em MatLab, para o cálculo numérico destes campos. Neste programa, o cálculo é feito pela integração numérica da lei de Biot-Savart. Com o auxílio do programa, nosso sistema apresenta as seguintes características. Temos como valores máximos: curvatura axial $\left(\approx 106 \mathrm{G} / \mathrm{cm}^{2}\right)$, gradiente radial $(\approx 117 \mathrm{G} / \mathrm{cm})$ e o campo de fundo axial $(\approx 140 \mathrm{G})$. Estes resultados estão compatíveis com a literatura, por exemplo, a referência [29]. O perfil de campo pode ser visto nas figuras $15,16,17$ e 18 para diferentes valores de compressão. A corrente, $I_{C}$, nas bobinas de compressão aumenta da figura 15 para 18 , conseqüentemente aumenta a compressão também.
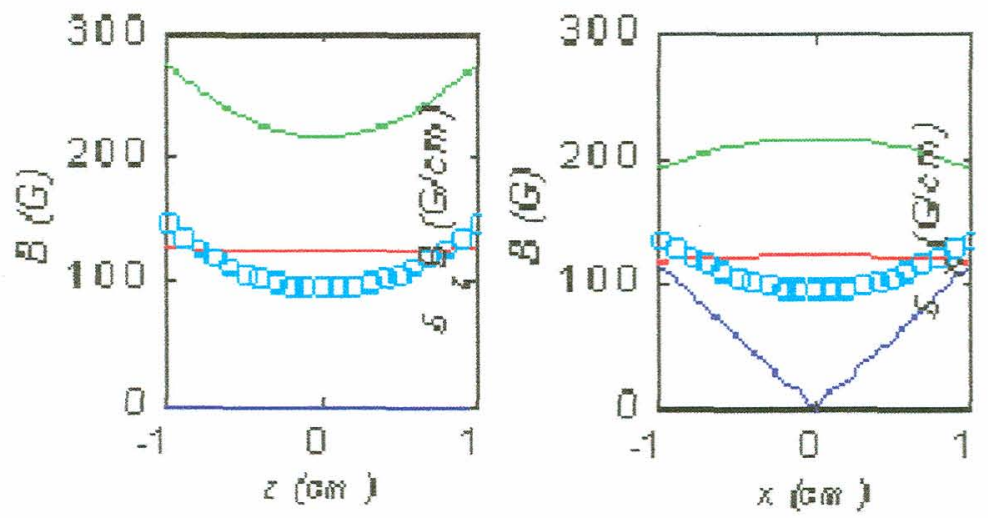

Figura 15: Simulação dos campos gerados pelas bobinas para o aprisionamento magnético, folha de trevo (azul), curvatura (verde), compressão (vermelho) e o campo total (círculos). $O$ corte da esquerda mostra o campo em $z$, eo da direita o corte na direção radial, $I_{C}=70 A$. 

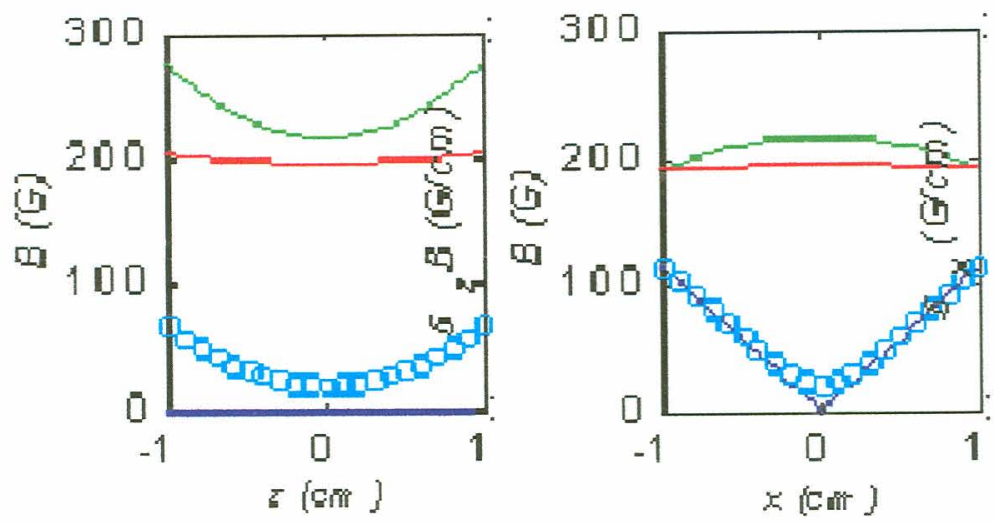

Figura 16: Simulação dos campos gerados pelas bobinas para 0 aprisionamento magnético. $I_{C}=90 A$. $I_{\text {TotaL }}=285 \mathrm{~A}$.
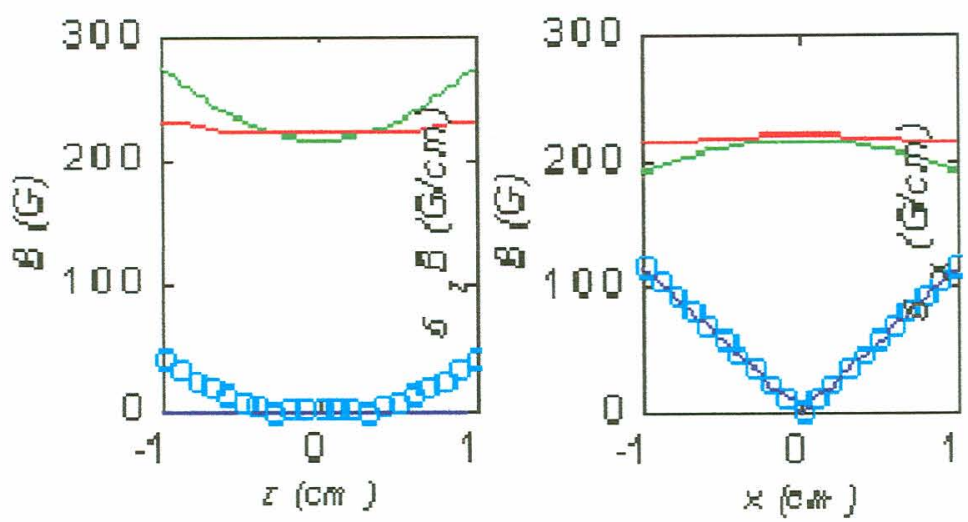

Figura 17: Simulação dos campos gerados pelas bobinas para 0 aprisionamento magnético. $I_{C}=100 A$. $I_{\text {TOTAL }}=285 A$.
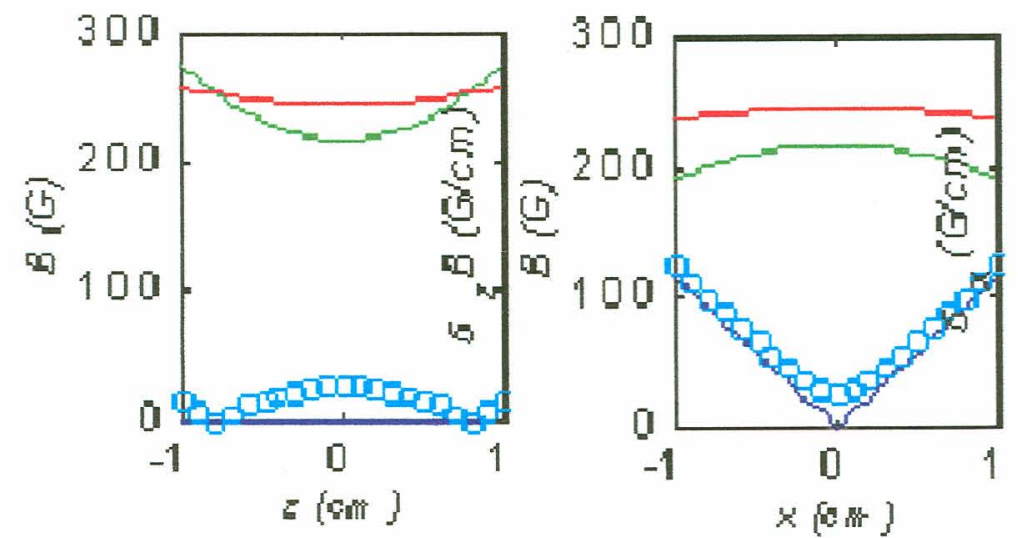

Figura 18: Simulação dos campos gerados pelas bobinas para 0 aprisionamento magnético. $I_{C}=120 A$. $I_{\text {TOTAL }}=285 \mathrm{~A}$. 


\section{III.3 - Sistema Mecânico do Feixe Atômico}

Para apresentarmos o sistema mecânico do feixe de maneira didática, vamos descrevê-lo da produção do feixe à frenagem.

Dentro de um recipiente metálico, chamado de forno, alguns gramas de sódio metálico foram aquecidos, por uma fita térmica, à temperatura de cerca de $350^{\circ} \mathrm{C}$, produzindo grande quantidade de vapor. Este vapor, impelido a sair do forno, passa por um "nozzle". Este é um estreito orifício, responsável pela colimação dos átomos em um feixe com um ângulo de abertura de aproximadamente $1 \mathrm{mrad}$. O "nozzle" é mantido a uma temperatura de $550^{\circ} \mathrm{C}$, superior à do forno, a fim de evitar entupimentos. Todo este conjunto foi montado em uma plataforma móvel dentro de uma câmara metálica com uma pressão parcial da ordem de $10^{-6}$ Torr mantida por um sistema de bomba difusora acoplada a uma bomba mecânica, figura 19 .

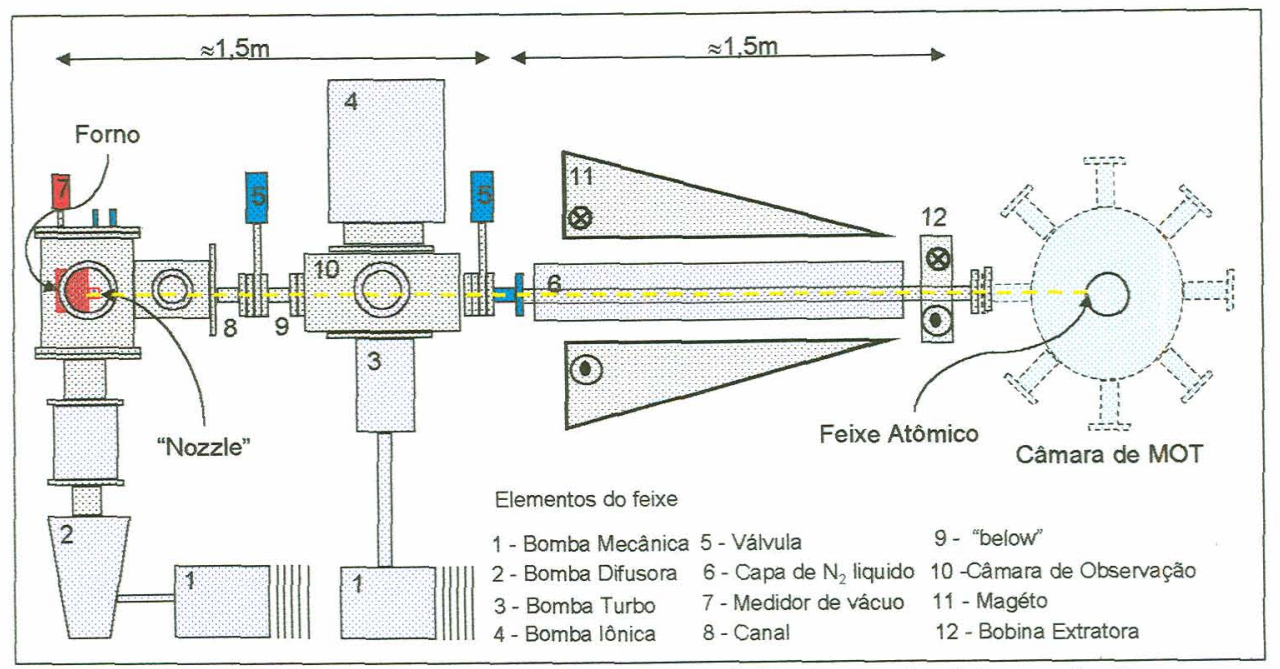

Figura 19: Visão geral do sistema de resfriamento do feixe atômico mostrando toda trajetória do feixe até chegar na câmara de MOT. 
Ao passar pelo "nozzle", o feixe encontra um orificio com cerca de $1,5 \mathrm{~mm}$ de diâmetro que liga a câmara do forno ao resto do sistema. Este orificio, chamado de canal, é mantido a $500^{\circ} \mathrm{C}$. O canal serve para evitar a passagem do vapor da câmara do forno para o restante do sistema, permitindo-nos a obtenção de uma menor pressão parcial neste segmento, ou seja, um melhor vácuo.

Uma segunda câmara encontra-se logo após o canal, possibilitando-nos, por meio de suas janelas, a observação e o alinhamento do feixe de frenagem em relação ao canal. Ela também possibilita a adição de uma bomba turbo molecular e uma bomba iônica, responsável pela queda da pressão parcial à cerca de $10^{-9}-10^{-10}$ Torr. Na sequiência, o feixe passa por um "bellow", um tubo flexível, responsável por evitar torções entre as partes conectadas. Após o "bellow" o feixe entra na região onde se promove a desaceleração. Nesta etapa, o feixe passa por um tubo metálico de aproximadamente $1,5 \mathrm{~m}$. Este tubo está envolto em uma camisa de $\mathrm{N}_{2}$ líquido para diminuir a pressão parcial no restante do sistema. Além disso, o tubo está rodeado pelo solenóide destinado à produção do campo magnético para o ajuste Zeeman. Uma fonte de 30 A fornece a corrente necessária para o solenóide e para a bobina extratora situada logo após o solenóide. Por fim, o tubo se conecta a câmara de aprisionamento, cujos detalhes serão apresentados no item seguinte. 


\section{III.4 - Sistema Mecânico do MOT}

Assim que o feixe passa pela bobina extratora ele penetra na câmara onde será realizado o MOT e a armadilha magnética. Esta câmara é construída em aço inoxidável e possui 18 janelas, figura20. Ligada a esta câmara temos duas bombas de vácuo iônicas e uma de sublimação de Ti, titânio, que promovem uma pressão parcial da ordem de $10^{-12}$ Torr.

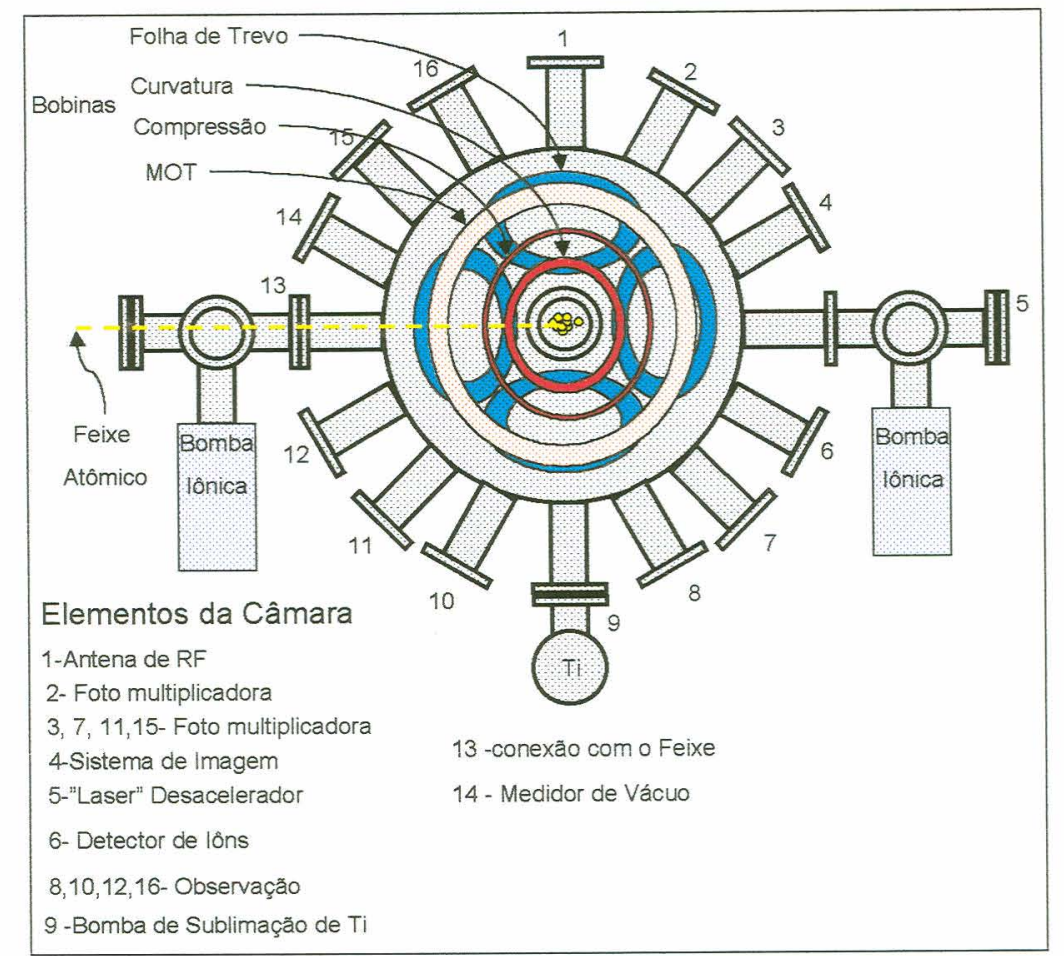

Figura 20: Câmara de MOT onde será feito o aprisionamento magneto-óptico e também o aprisionamento magnético. 


\section{III.5 - Sistema Elétro-eletrônico do MOT}

Como já foi citado, item III.1, um dos momentos mais importantes no experimento são as transferências do MOT para a armadilha magnética. Para que isso ocorra da maneira desejada é necessário que as correntes que passam pelas bobinas do MOT, que geram os gradientes de campo, sejam desligadas em um intervalo de tempo menor que $1 \mathrm{~ms}$. A corrente que passa pelas bobinas do MOT é de aproximadamente $30 \mathrm{~A}$, então, para chavearmos este sistema via microcomputador construímos o sistema da figura 21. Ligado em série com as bobinas, conectamos um "MOSFET" e para controlarmos este sistema via microcomputador, construímos um controlador idêntico ao construído para os IGBTs, figura 23 .

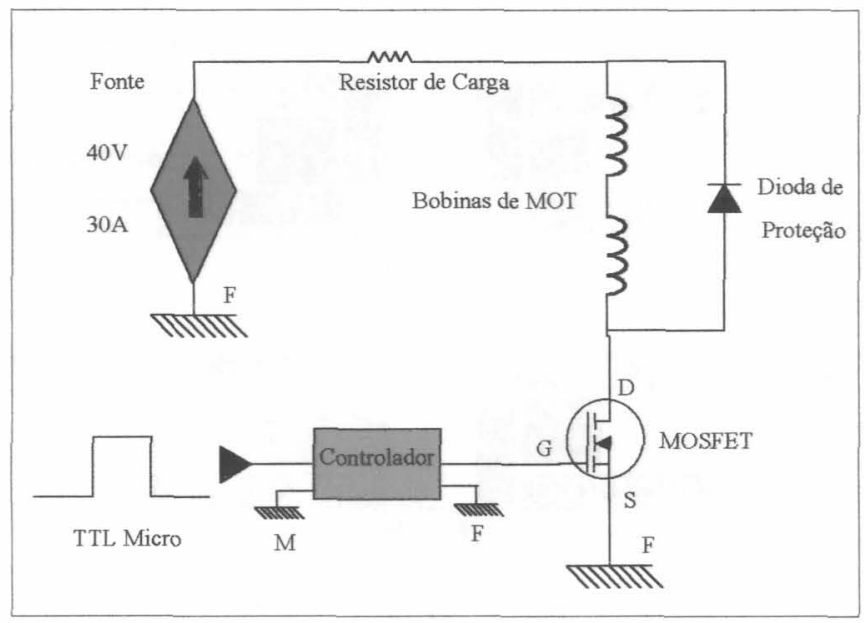

Figura 21: Sistema de controle das bobinas de MOT e a configuração do sistema elétrico. 


\section{III.6 - Sistema Mecânico da Armadilha Magnética}

O primeiro dos problemas enfrentados por nós na construção do sistema de aprisionamento magnético foi encontrar as dimensões adequadas para as bobinas. Na simulação, item III.2, dos campos necessários encontramos as dimensões ideais, no entanto, precisamos adaptá-las às dimensões da câmara. Outro problema foi a elaboração dos suportes para prender as bobinas na câmara e também em como fazer as conexões elétricas e hidráulicas. Esta foi, sem dúvida uma das etapas mais críticas, pois todas as características do campo dependem diretamente desta configuração. Na figura 22 , temos um corte transversal da câmara com as bobinas e para uma melhor visualização podemos compará-la com a figura 20 .

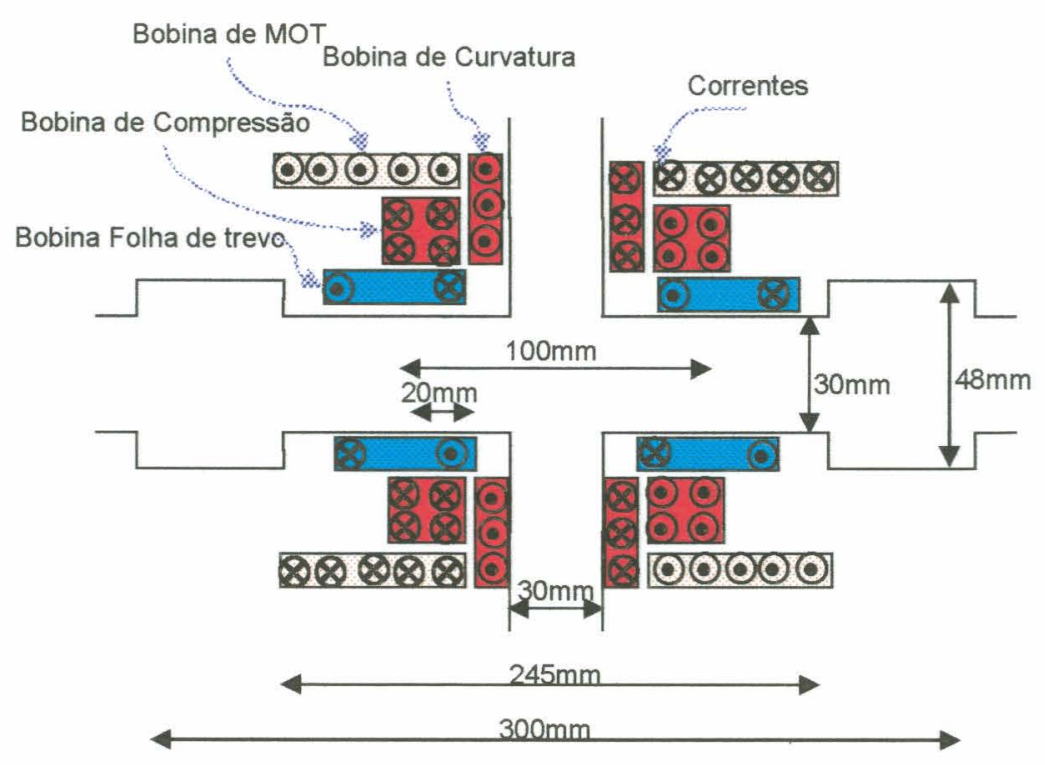

Figura 22: Configuração espacial das bobinas em relação à câmara. 
As bobinas foram construídas com tubos de cobre com aproximadamente 5 $\mathrm{mm}$ de diâmetro e para o isolamento elétrico foram utilizadas borrachas termocompressiveis. Eletricamente as bobinas estão conectadas entre si por cabos de aproximadamente $10 \mathrm{~mm}$ de diâmetro, pois por cada Bobina irão passar $300 \mathrm{~A}$ de corrente. Todas as bobinas do sistema, quando ligadas, dissipam em torno de $6 \mathrm{~kW}$ de potência elétrica. Para refrigerarmos as bobinas passamos, pelo interior dos tubos, água a alta pressão. $O$ resistor de carga utilizado em nosso sistema foi construído com um tubo de aço inoxidável e refrigerado passando-se água pelo seu interior.

\section{III.7 - Sistema Eletro-eletrônico da Armadilha Magnética}

Para a operação do sistema devemos entender os dois modos diferentes de operá-lo. Primeiro, pelos motivos citados no item III.1, devemos ligar ou desligar nosso sistema rapidamente, em um tempo menor que $1 \mathrm{~ms}$. Segundo, quando estiver ligado, devemos ser capazes de variar a corrente nas bobinas de compressão para realizarmos a compressão adiabática, e com uma estabilidade na corrente de pelo menos $1 \mathrm{em} 10^{4}$. Além de tudo, este sistema não daria para ser controlado manualmente, pois devemos sincronizá-los com todo o resto. Então foi necessária a construção de uma interface para controlarmos tudo via microcomputador.

Basicamente são só estas as características necessárias. Entretanto, quando se passa 300 A de corrente pelo nosso sistema tal tarefa deixa de ser trivial. 


\section{III.7.a - Sistema de Chaveamento}

Neste item vamos nos preocupar em como ligar e desligar a corrente de 300 A, em menos de $1 \mathrm{~ms}$, que passa pelas bobinas. Fisicamente o sistema tem características intrinsecas, que não podemos alterar. Este acaba sendo o primeiro fator limitante. Todas as bobinas ligadas na configuração desejada possuem uma indutância $\mathrm{L}=60 \mu \mathrm{H}$. Se desligarmos ou ligarmos o sistema no tempo de chaveamento de transistores comuns, $\Delta t \approx \ln$, temos uma força eletromotriz induzida da ordem de $\varepsilon_{\mathrm{fem}} \approx 50 \mathrm{kV}$, o que torna esta tarefa dificil. Um outro fato que devemos lembrar é que nosso sistema é um circuito RLC. Teremos então um tempo $\tau$ $\approx 10^{-4} \mathrm{~s}$ de desligamento e uma freqüência de ressonância $\omega \approx 10^{6} \mathrm{rad} / \mathrm{s}$. Antes de fazermos qualquer proposta para a configuração elétrica de nosso sistema devemos levar essas informações em consideração.

Além das características especificas do nosso sistema de bobinas, devemos levar em consideração as especificações da fonte de corrente para a alimentação. A fonte é um modelo comercial, fornecendo 300 A contínuos. É possível chaveá-la diretamente, entretanto, com um tempo muito longo comparado com os tempos de ligamento e desligamento que necessitamos. Uma outra caracteristica é que a fonte só pode ser operada com carga. Todas estas necessidades na configuração e nas características do sistema, assim como as especificações da fonte tornam a 
implementação deste sistema uma tarefa extremamente dificil do ponto de vista experimental.

\section{III.7.a.1 - Configuração}

A configuração deste sistema é conseqüência direta de como solucionamos os problemas experimentais para obtermos as características necessárias para o aprisionamento magnético. Para uma melhor observação de quais foram os problemas e como os solucionamos vamos enumerá-los, lembrando que estes são problemas que tivemos que enfrentar antes da construção. Problemas: $1^{\circ}$ ligar/desligar $300 \mathrm{~A} \mathrm{em} 1 \mathrm{~ms}, 2^{\circ}$ a fonte de corrente não funciona sem carga e $3^{\circ}$ força eletromotriz induzida muito alta.

Soluções: Para chavearmos o sistema em $1 \mathrm{~ms}$ ou menos ligamos as bobinas diretas na fonte e utilizamos uma chave de liga/desliga rápida, no caso um IGBT. Mas a fonte não iria funcionar quando a chave estivesse aberta. Para resolvermos isto, ligamos as bobinas em paralelo com um resistor de carga e, neste ramo, também adicionamos uma chave liga/desliga, IGBT. Então, nesta configuração, ora a corrente passa pela bobina, ora passa pelo resistor de carga, não acarretando problemas para a fonte. Lembramos que o resistor de carga deve ter a mesma resistência das bobinas para que a fonte não sinta o chaveamento.

Quanto à força eletromotriz induzida, utilizamos duas saidas: os varistores e uma resistência de amortecimento. Varistor é um dispositivo que, abaixo de uma determinada tensão aplicada, comporta-se como um circuito em aberto. Acima desta 
tensão ele comporta-se como um resistor de resistência variável a fím de manter sempre a mesma tensão aplicada sobre seus terminais. Adicionando estes elementos em paralelo com as bobinas e com os IGBTs, então forçamos um caminho de fuga para a corrente durante o chaveamento. A potência dissipada pelo varistor é um fator determinante na taxa em que podemos fazer o chaveamento. Lembrando que nosso sistema comporta-se como um circuito RLC, colocamos uma resistência de amortecimento em paralelo com as bobinas. Esta resistência é para que tenhamos um comportamento de um oscilador harmônico amortecido criticamente, no momento do chaveamento. Estas soluções encontradas nos ajudam em parte, pois quanto mais elementos adicionamos ao sistema, maiores serão as dificuldades de sincronismo e interação com o mesmo.

O IGBT é um dispositivo que pode ser usado como uma chave liga/desliga extremamente rápida. Aplicando-se uma tensão, $5 \mathrm{~V}$ a $15 \mathrm{~V}$, no "gate" ele passa a conduzir corrente entre os terminais. Abaixo desta tensão o IGBT funciona como uma chave em aberto. Uma característica importante no IGBT é a máxima tensão a que o dispositivo pode estar sujeito sem danificar-se, conhecido como $\mathrm{V}_{\mathrm{DS}}$ (tensão “dreno-source"). O V $\mathrm{V}_{\mathrm{DS}}$ dos IGBTs usados por nós é da ordem de 500 volts, este é, um dos principais fatores pelo qual escolhemos este dispositivo, pois mesmo utilizando os varistores a força eletromotriz induzida ainda está presente

Para controlarmos os IGBTs via microcomputador devemos ter o cuidado de isolar as referências, terra da fonte e o do terra do microcomputador, pois qualquer descuido poderia gerar correntes indesejáveis passando pelo microcomputador. Uma maneira alternativa de evitar isto é utilizar um opto-acoplador com características 
específicas para controlar os IGBTs. Utilizando este dispositivo construímos um pequeno circuito de controle ("drive"), figura 23(a), onde entramos com um sinal TTL $(0 \mathrm{~V}$ ou $+5 \mathrm{~V})$ e saímos com um sinal de $0 \mathrm{~V}$ ou $+15 \mathrm{~V}$ para o "gate" do IGBT, terminal de disparo. Para facilitarmos a notação nos próximos itens vamos denominar IGBT1 e controlador 1 para o resistor de carga e IGBT2 e controlador 2 para as bobinas.

\section{III.7.a.2 - Sincronização dos Sinais}

O sinal que recebemos do microcomputador, para o chaveamento, é um sinal do tipo TTL indicando o momento em que as bobinas devem ser ligadas. Enquanto temos o sinal de $+5 \mathrm{~V}$ devem passar correntes pelas bobinas e quando o sinal for de $0 \mathrm{~V}$ a corrente deverá passar pelo resistor de carga. Temos aqui então um problema de sincronização para resolver.

$\mathrm{Na}$ prática isto corresponde à construção de um sistema de controle da seguinte maneira: quando temos o sinal $+5 \mathrm{~V}$ vindo do microcomputador devemos ter o sinal de entrando no controlador 2 e saindo dele um sinal de $+15 \mathrm{~V}$ indo para o IGBT2, então temos a corrente passando pelas bobinas. Quando o sinal do micro for OV devemos ter um sinal entrando no controlador 1 e saindo dele um sinal de $+15 \mathrm{~V}$ indo para o IGBT1, então teremos a corrente passando pelo resistor de carga. Para resolvermos isto construímos um circuito inversor. Quando temos o sinal $+5 \mathrm{~V}$, TTL do microcomputador, temos um sinal que vai para o controlador 2 e quando o sinal 
do microcomputador for de $0 \mathrm{~V}$ geramos um sinal de $+5 \mathrm{~V}$ que vai para o controlador 1.

No mesmo instante em que desligamos a corrente nas bobinas devemos ligar a corrente que passa pelo resistor de carga e vice-versa. Poderíamos pensar em sincronizar diretamente os IGBTs, mas como as características, indutância e resistência, são diferentes de um ramo para o outro, conseqüentemente os tempos de desligamento serão diferentes.

Para solucionarmos estes problemas construímos um circuito de atraso ("delay"), onde podemos ajustar os atrasos de um sinal em relação a outro. Juntando estes dois circuitos, inversor e de atraso, construímos uma espécie de circuito de atraso para sincronizarmos os sinais, figura 23(b). Então para o controle

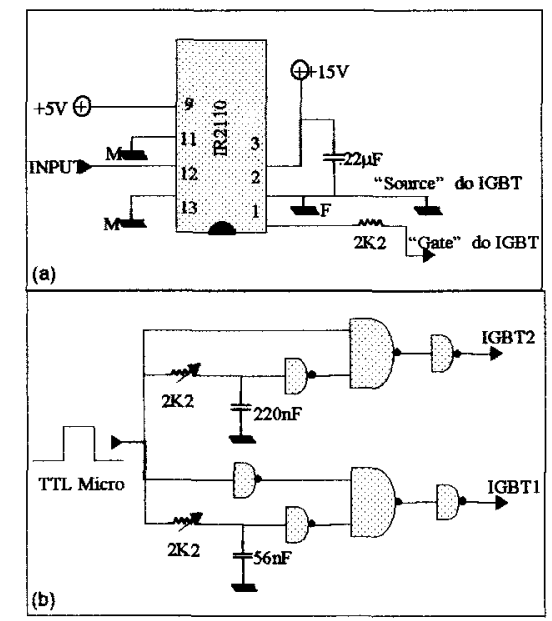

Figura 23: (a) Circuito de controle dos IGBTs, (a) Circuito de atraso.

do sistema de chaveamento temos a seguinte seqüência: sinal TTL do microcomputador, circuito de atraso, controlador dos IGBTs e por fim o sinal chega aos IGBTs. Na figura 25 temos uma visão geral do sistema. 


\section{III.7.b - Sistema de Compressão}

Resolvido o problema do chaveamento, precisamos agora nos preocupar com quando as bobinas estão ligadas e com como será feita a compressão adiabática.

Foi preciso elaborar um sistema em que pudéssemos variar as correntes que passam pelas bobinas de compressão (ou “anti-bias") sem variarmos a corrente que passa pelas outras bobinas. Para isto optamos pela configuração das bobinas como descrito na figura 21, que nos dá uma descrição geral do sistema. As duas bobinas de compressão em paralelo entre si e em série com as outras bobinas.

Para a construção do sistema desejado precisamos construi-lo com características compatíveis com as nossas necessidades que são as seguintes: a corrente que passa por cada bobina de compressão deve variar ente 0 a $150 \mathrm{~A}$; a estabilidade de corrente deve ser pelo menos 1 em $10^{4}$. Aparentemente estas características parecem ser facilmente conseguidas. Entretanto, quando temos que levar em consideração a tamanha complexidade geral do sistema e as altas correntes envolvidas, torna-se um problema difícil.

Para a sincronização dos sistemas devemos controlar a variação de corrente das bobinas de compressão via microcomputador. Para isso, foi necessária a construção de um circuito de controle. O único sinal que temos do micro é uma rampa de tensão que varia de $0 \mathrm{~V}$ a $10 \mathrm{~V}$ e a partir deste sinal devemos ser capazes de 
variar a corrente de $0 \mathrm{~A}$ a $150 \mathrm{~A}$ em cada bobina de compressão. $\mathrm{O}$ primeiro cuidado a ser tomado é quanto ao isolamento das referências, terra. O terra do microcomputador deve estar isolado do terra da fonte para evitarmos que correntes indesejáveis passem pelo microcomputador. Para isto, utilizamos um opto-acoplador, entretanto, este deve ter uma transferência linear do sinal para que a variação do sinal da rampa tenha uma variação proporcional na corrente de cada bobina. $O$ controlador linear está descrito na figura 24. Ele é basicamente um circuito de "feedback", temos o sinal que vem a partir de um resistor de referência, reflete a corrente que passa pelo "MOSFET" e o sinal é utilizado para realimentar o sistema.

Após vários "loops" temos o circuito estabilizado. Quando o sinal que vem do microcomputador é alterado, a tensão sobre o resistor de referência é alterada e novamente o circuito é realimentado até o sistema estabilizar-se em uma determinada corrente. A partir da construção deste circuito fazemos uma curva de calibração, para cada tensão que vem do microcomputador medimos qual a tensão sobre o resistor de referência. Então, saberemos qual a corrente em cada bobina. Para evitarmos que a corrente que passa por uma bobina seja diferente da outra, construímos resistências ajustáveis ao final de cada bobina para reduzirmos as diferenças entre as resistências internas de cada uma. Na figura 25 , podemos ter uma visão geral de todo o sistema. 


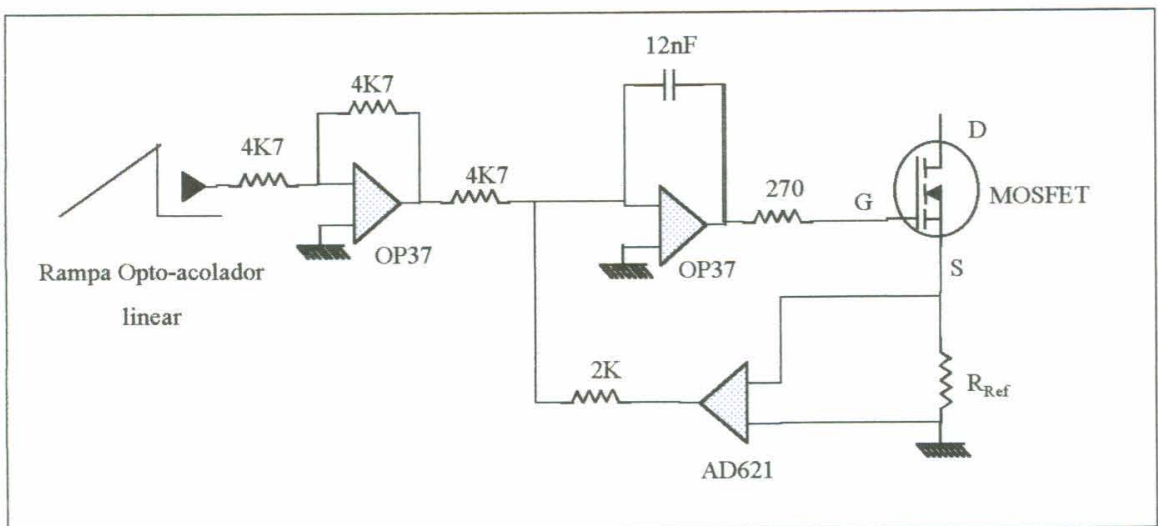

Figura 25: Circuito de controle do MOSFET para que tenhamos uma variação linear de corrente nas bobinas de compressão.

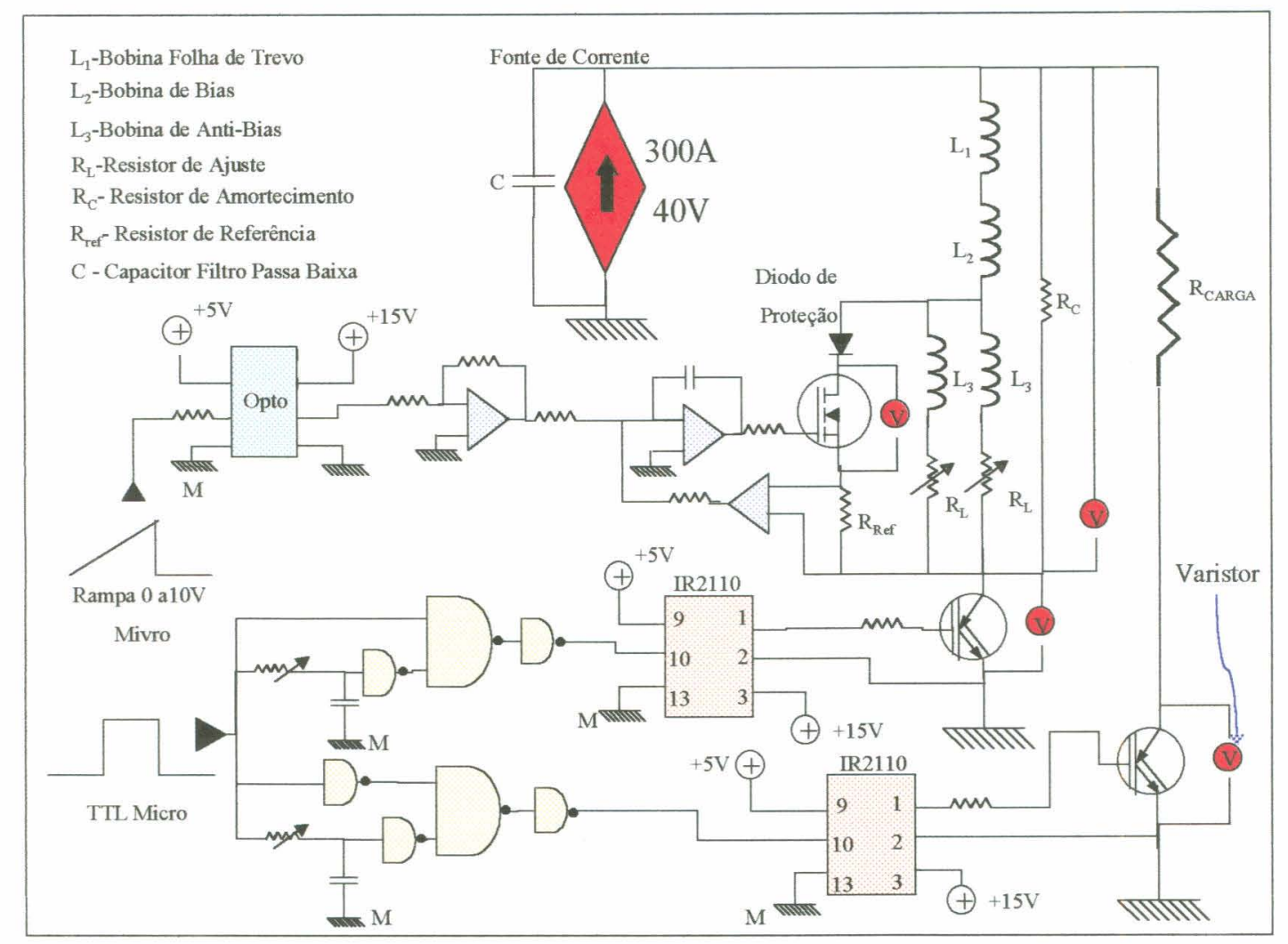

Figura 25: Visão geral do sistema elétrico das bobinas e os sistemas de controle do mesmo. 


\section{IV - Caracterização e Aprisionamento}

Neste capítulo vamos caracterizar eletricamente o nosso sistema de bobinas para verificarmos o quanto ele está dentro do esperado. Também apresentaremos os resultados do aprisionamento e os indícios de compressão.

\section{IV.1 - Caracterização do Sistema Eletro-eletrônico}

Antes de iniciarmos qualquer transferência do MOT para a armadilha magnética, é preciso que as características do sistema estejam de acordo com o esperado. Então iremos fazer uma caracterização de nosso sistema. Antes de tudo é preciso saber como as bobinas de MOT estão sendo desligadas.

\section{IV.1.a Caracterização do Sistema de MOT}

O sistema de chaveamento do sistema de MOT está descrito na figura 17. Antes de caracterizarmos o chaveamento vamos às características fisicas do sistema: $\mathrm{R}_{\mathrm{CARGA}}=1,5 \Omega$ e a indutância em cada bobina vale $\mathrm{L}=25 \mu \mathrm{H}$, na montagem as bobinas 
e o resistor estão em série. Para caracterizarmos o sistema medimos a tensão entre os terminais, "dreno" e o "source", do MOSFET, durante o chaveamento utilizando um osciloscópio digital. Então, quando o circuito estiver aberto, deveremos observar uma tensão diferente de zero e quando o circuito estiver fechado a tensão observada deverá ser nula. Nas figuras 26(a) e 26(b) observamos a tensão quando o sistema está sendo desligado. As figuras 26(c) e 26(d) apresentam o sistema sendo desligado, com resolução temporal diferente.

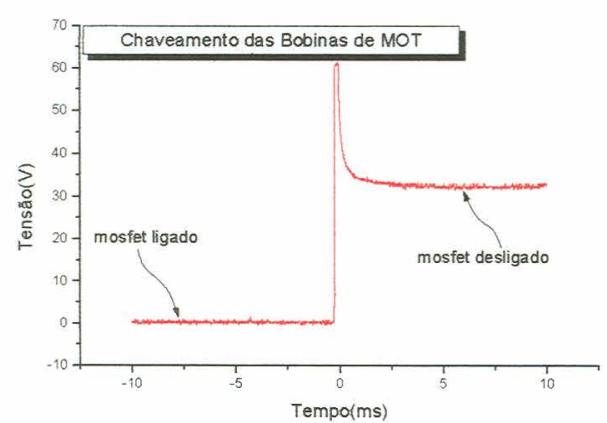

(a)

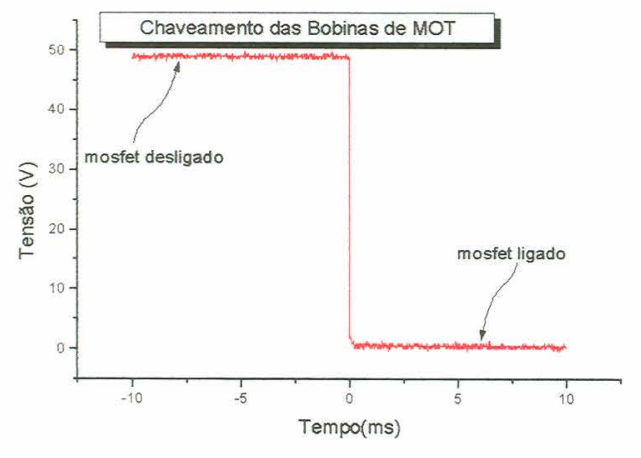

(c)

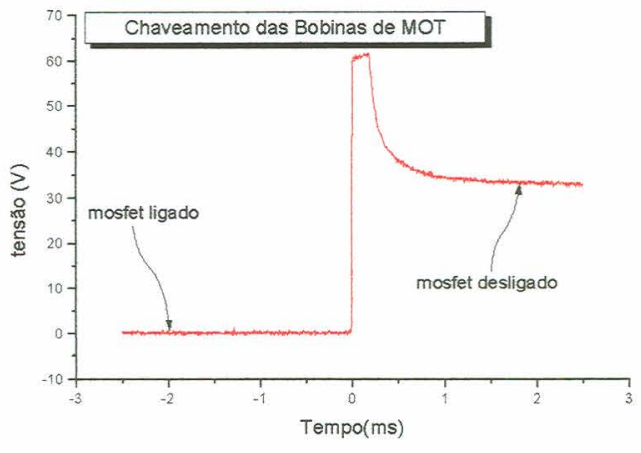

(b)

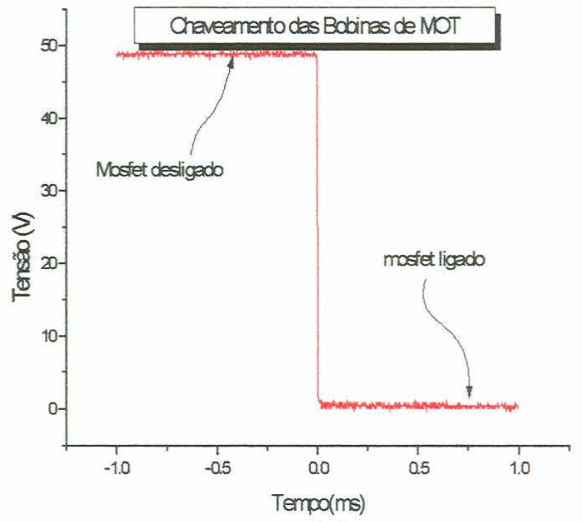

(d)

Figura 26: $V_{D S}$ no MOSFET do sistema de chaveamento do MOT: (a) e (b) quando o sistema esta sendo desligado e com resolução temporal diferente, (c) e (d) Sistema sendo ligado.

Vemos pelas figuras 26(a), 26(b), 26(c) e 26(d) que o tempo de chaveamento é o suficiente para iniciarmos a transferência, mesmo havendo a presença de um pico 
de tensão quando desligamos, devido à força eletromotriz induzida, pois desaparece em menos de $1 \mathrm{~ms}$

\section{IV.1.b Caracterização da Armadilha Magnética}

Esta caracterização é fundamental para o aprisionamento magnético dos átomos, pois é a partir dela que saberemos se o sistema é viável para o aprisionamento e como o faremos. Vamos nos preocupar primeiro com o chaveamento observando a tensão entre os terminais, "gate" e o "source", do IGBT, idêntico ao que fizemos para o MOT. Entretanto, temos que garantir que variações de tensão são, necessariamente, variações de corrente. Para isto, adicionamos um resistor em série com os IGBTs, só durante este teste, e observamos a tensão sobre o resistor e sobre o IGBT ao mesmo tempo. Então, medimos a tensão sobre os terminais do IGBT e a tensão sobre o resistor de teste, figuras 27 e 28.

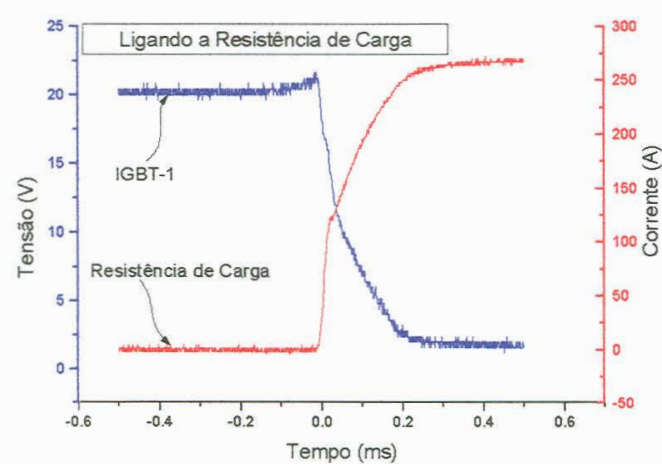

(a)

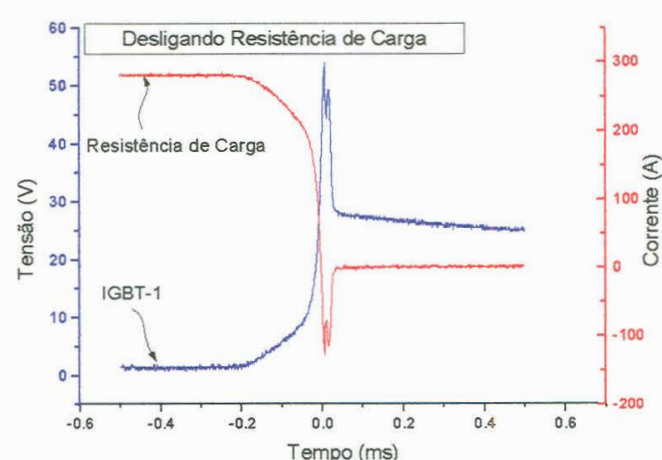

(b)

Figura 27: $V_{D S}$ no IGBT1 e tensão sobre o resistor de carga: (a) quando fechamos o circuito, (b) quando abrimos o circuito. 


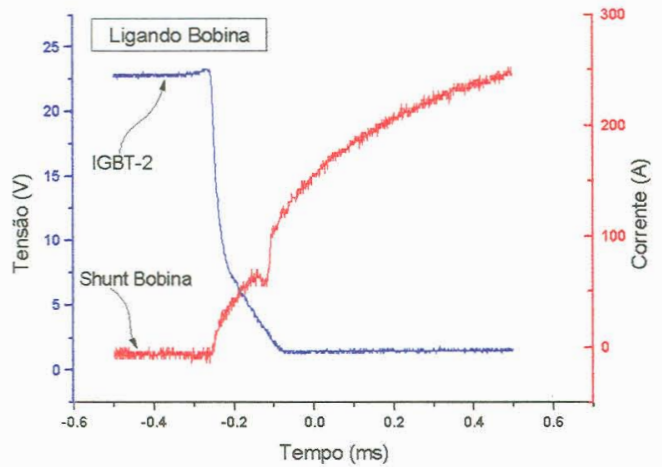

(a)

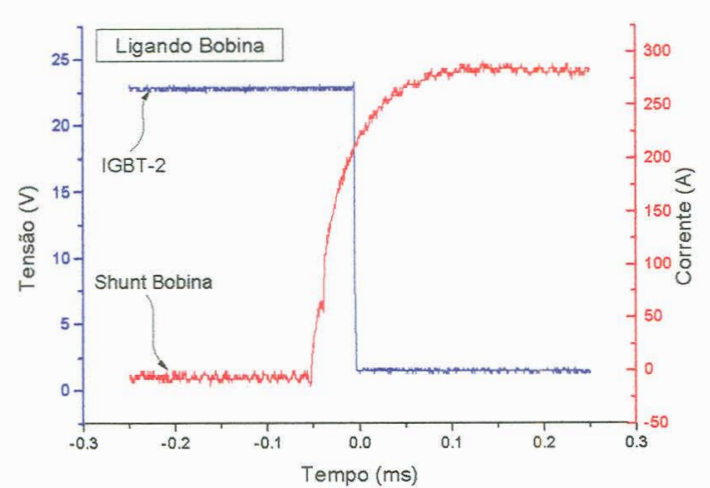

(b)

Figura 28: $V_{D S}$ no IGBT2 e tensão sobre o resistor de teste: (a) quando fechamos o circuito, (b) quando abrimos o circuito.

Então, pelas figuras 27 e 28 concluímos que a variação de tensão medida estará diretamente relacionada com a corrente. Tomada esta precaução vamos à caracterização do sistema propriamente dita. Iremos então, observar a sincronização dos $V_{D S}$ nos IGBTs. É fundamental que quando um IGBT estiver sendo ligado o outro esteja sendo desligado, para que não ocorram variações bruscas de corrente na fonte. Variações bruscas de corrente na fonte irão provocar variações de corrente nas bobinas, alterando as configurações de campo desejadas. Nesta medida, observamos a variação do $\mathrm{V}_{\mathrm{DS}}$ dos IGBTs ao mesmo tempo. Para sincronizarmos os tempos utilizamos o circuito de atraso até encontrarmos uma boa configuração. Lembrando que IGBT1 refere-se ao resistor de carga e IGBT2 refere-se às bobinas.

Do ponto de vista dos átomos, o momento mais crítico é quando ligamos as bobinas, pois variações lentas de corrente são sentidas pelos átomos. Para o sistema de controle quando, desligamos a bobina, que é o ponto crítico, pois a força eletromotriz induzida produz grandes variações de tensão. Nas figuras 29 e 30 podemos observar a sincronia dos IGBTs. Nas figuras 29(a) e 29(b), temos a tensão 
entre os terminais, $V_{D S}$, quando as bobinas são ligadas. Vemos que em torno de $1 \mathrm{~ms}$ a corrente já está estabilizada sem haver variações bruscas de corrente, sinal no IGBT2. Nas figuras 30(a) e 30(b), mostramos a tensão $V_{D S}$ sobre os IGBTs quando o sistema está desligado. Podemos ver que os varistores entram em ação ceifando as altas tensões induzidas e também o resistor de amortecimento crítico contribui para evitarmos as oscilações.

A última caracterização do sistema a ser feita é observarmos a flutuação de corrente da fonte.

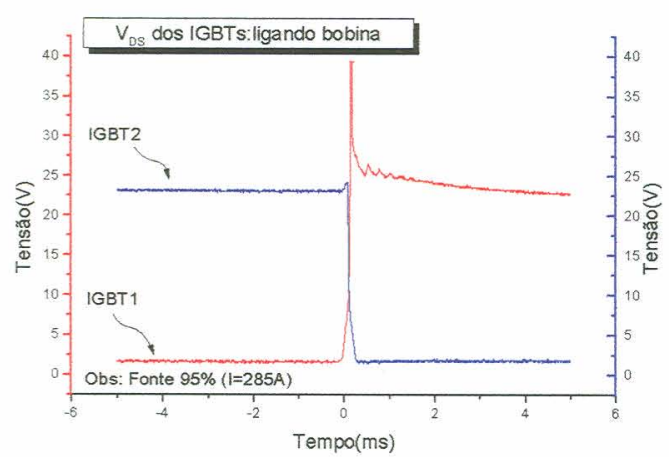

(a)

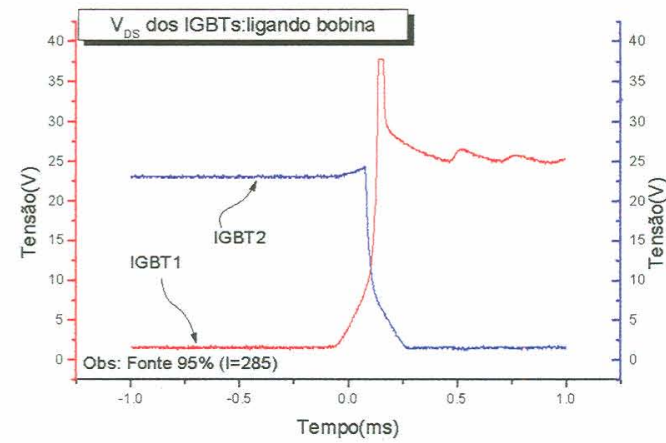

(b)

Figura 29: $V_{\mathrm{DS}}$ dos IGBTs 1 e 2, quando as bobinas estão sendo ligadas com resolução temporal diferente.

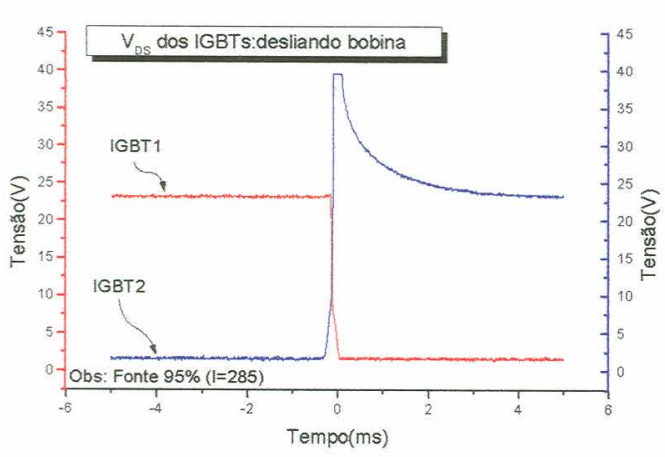

(a)

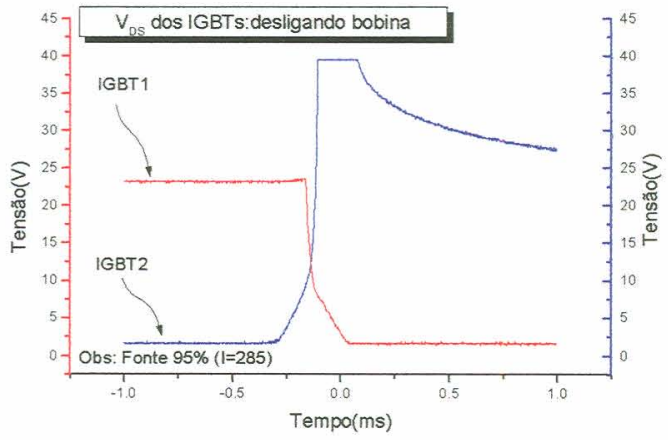

(b)

Figura 30: $V_{\mathrm{DS}}$ dos IGBTs 1 e 2, quando as bobinas estão sendo desligadas com resolução temporal diferente. 
Para observarmos as flutuações de corrente na fonte, adicionamos alguns resistores para teste. Logo na saída da fonte adicionamos um resistor em série com todo o sistema. No ramo das bobinas, logo acima delas, adicionamos outro resistor de teste. Então, vamos medir simultaneamente a tensão sobre os resistores. Nas figuras 31(a) e 31(b), vemos a flutuação de corrente da fonte, que é da ordem de 10\%. Mas acreditamos não ter grande influência sobre os átomos a ponto de comprometer o aprisionamento magnético.

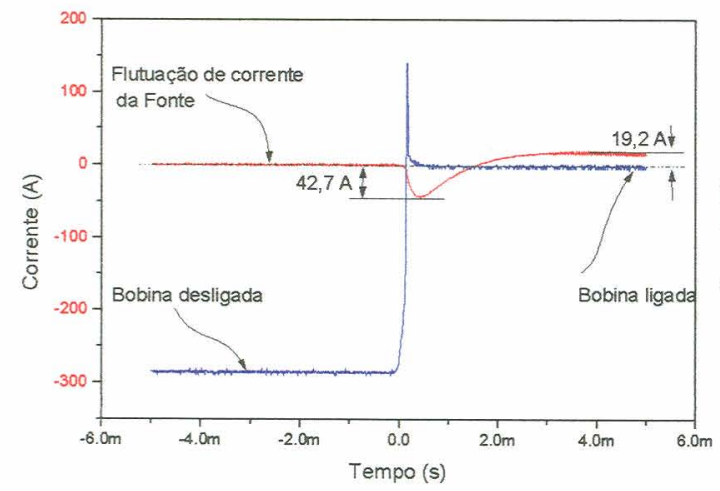

(a)

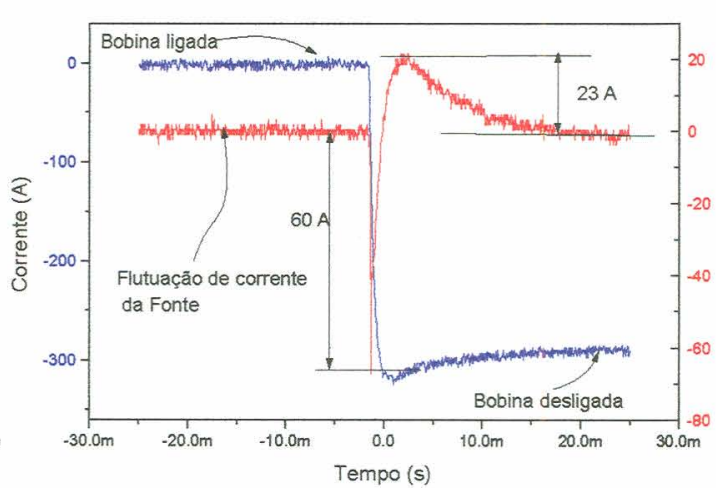

(b)

Figura 31: Flutuação de corrente da fonte durante o chaveamento, (a) quando as bobinas estão sendo ligadas, (b) quando as bobinas estão sendo desligadas.

Caracterizado o sistema de chaveamento da corrente, vamos agora caracterizar o sistema quando as bobinas estiverem ligadas, ou seja, vamos observar a compressão. Esta caracterização é feita da seguinte maneira. Para cada tensão que o microcomputador envia para o controlador do MOSFET, medimos a tensão sobre o resistor de referência e assim sabemos quanto de corrente passa em cada bobina de compressão. Este resultado está apresentado na figura 32. Observamos pela figura uma resposta linear do sistema de compressão, o que era desejado. Feito isto, 
podemos passar para o aprisionamento magnético, pois com estas caracterizações verificamos que o sistema está dentro do esperado.

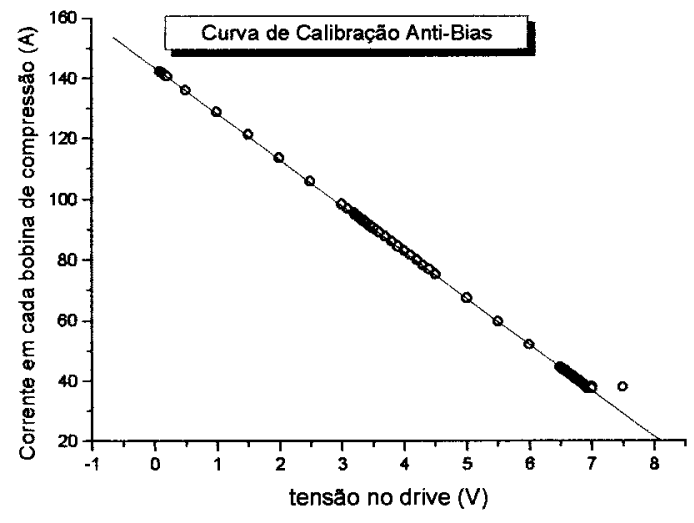

Figura 32: Curva de calibração do sistema de compressão.

\section{IV.2 - Tempo de Vida e Imagem}

Uma primeira observação que podemos fazer sobre os átomos aprisionados é medir o tempo de vida. Como foi apresentado na figura 14, para medirmos o tempo de vida da armadilha magnética é só variarmos o tempo em que as bobinas estão ligadas e fazermos uma imagem, visto que, o número de átomos depende da fluorescência.Com uma câmera CCD medimos a intensidade da fluorescência e, então, observamos a variação do número de átomos na armadilha. Na figura 33 , temos uma medida de tempo de vida. Com $\tau \approx 1 \mathrm{~s}$, que é um tempo pequeno. Entretanto, o valor de $\tau$ é compatível com a pressão parcial da câmara que é da ordem de $10^{-9}$ Torr. 


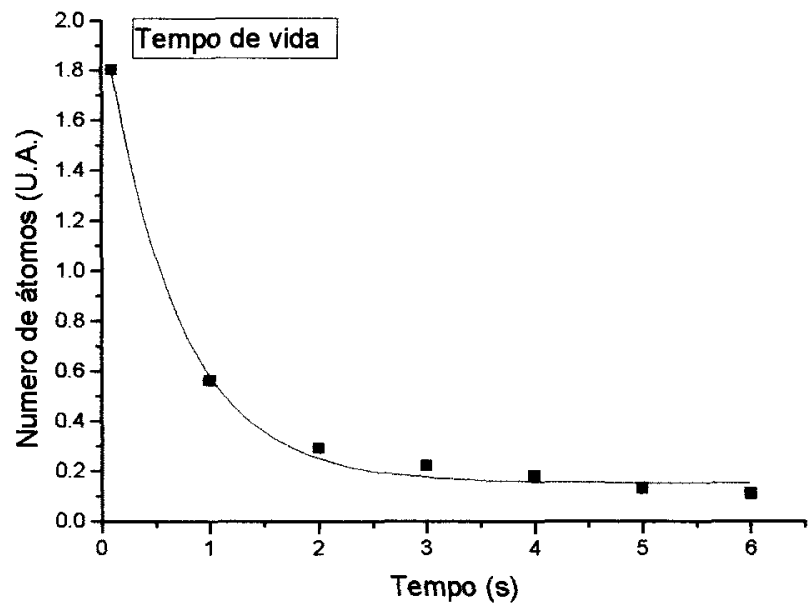

Figura 32: Medida do tempo de vida da armadilha magnética, número de átomos em unidades arbitrárias em função do tempo, $\tau \approx 1 \mathrm{~s}$.

Agora, para medirmos a compressão adiabática, vamos observar as imagens da armadilha magnética, variando a corrente que passa pelas bobinas de compressão. O procedimento foi o seguinte. Quando fizemos a transferência já havia um determinado valor de corrente nas bobinas de compressão e então foi feita uma imagem dos átomos. Novamente, fizemos outra transferência já com uma corrente passando pelas bobinas de compressão, só que diferente da anterior. Em nosso caso, variamos a corrente em cada bobina de $70 \mathrm{~A}$ até $140 \mathrm{~A}$, onde a compressão era máxima. Estas imagens estão apresentadas na figura 34 , ao lado da imagem. A imagem feita pela câmera CCD nos mostra a intensidade em cada "pixel", para uma melhor visualização da imagem ela foi colorida artificialmente. Podemos ver a imagem da câmera CCD, observando o perfil de intensidades dos "pixels" em função da posição, figura 34. Na figura 34 , vemos claramente o perfil de intensidade ser 
alongado formando dois picos de máximo. Como a intensidade da fluorescência é proporcional ao número de átomos, então, na figura observamos a distribuição dos átomos ao longo do potencial.
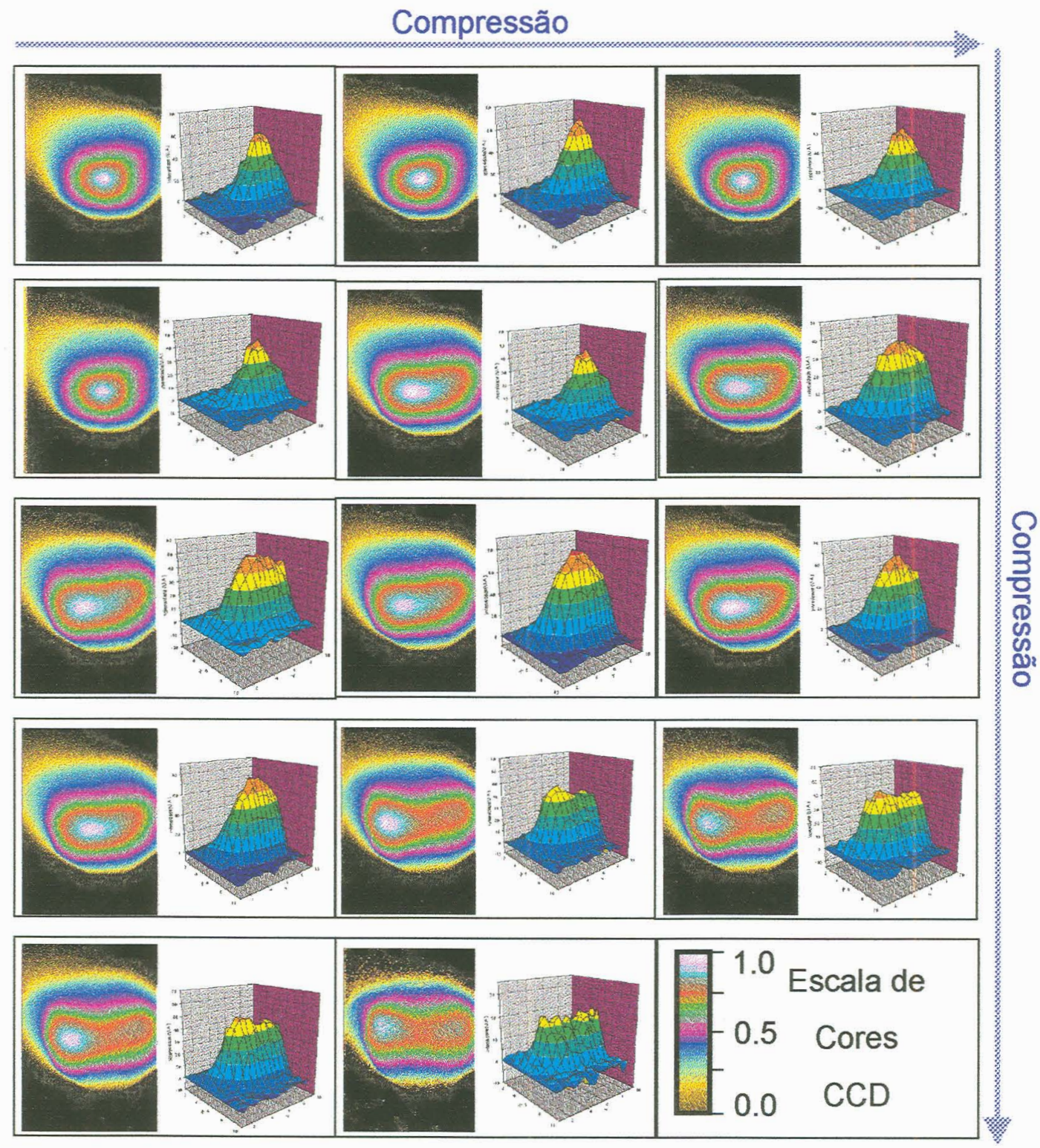

Figura 34: Imagem da armadilha magnética variando-se a corrente nas bobinas de compressão, de 70A a 140A. Ao lado das imagens temos os perfis de intensidade das imagens. 


\section{V - Conclusões}

Primeiramente, vamos analisar a caracterização elétrica do sistema de bobinas. Na figura 26 , onde temos o tempo de chaveamento do MOT, observamos que o tempo de desligamento do sistema é suficiente para iniciarmos a transferência. Quanto ao sistema da armadilha magnética, os tempos estão de acordo com o esperado, figuras 29 e 30 . Em menos de $1 \mathrm{~ms}$, já temos as correntes necessárias para o aprisionamento magnético. Entretanto, há uma considerável flutuação de corrente na fonte durante o chaveamento. Além disso, essa flutuação é lenta, mais de $1 \mathrm{~ms}$, o suficiente para os átomos perceberem. Mas, de acordo com as simulações, essas flutuações não promovem alteração considerável no perfil do campo. Observando a figura 32 , vemos que a corrente que passa pelas bobinas de compressão varia de maneira linear. De acordo com essas características, o sistema está apto para iniciar o aprisionamento.

O tempo de vida medido para a armadilha magnética, $\tau \approx 1 \mathrm{~s}$, ainda é um tempo muito pequeno para os nossos objetivos. Para a realização da CBE, o tempo deveria ser de, no mínimo, 40s. Entretanto, este tempo está compatível com a pressão parcial no interior da câmara, $P \approx 10^{-9}$ Torr. Este pequeno tempo de vida nos trará 
alguns problemas para a verificação da compressão adiabática. Vamos agora analisar as imagens de compressão, figura 34.

Antes, é preciso compreender que a compressão adiabática é um processo dinâmico. Quando os átomos são comprimidos adiabaticamente no potencial, a densidade no espaço de fase deve permanecer constante, só aumentando a temperatura. Fazendo a descompressão dos átomos, a temperatura deve voltar ao valor que tinha antes da compressão, se esta foi feita de maneira adiabática. Então, uma maneira de verificarmos se houve a compressão adiabática em nosso sistema é a seguinte: fazer uma imagem dos átomos aprisionados, comprimir e descomprimir o potencial e, novamente, fazermos uma imagem. A partir da imagem final/inicial, poderíamos verificar a temperatura da amostra nos dois casos. Se a temperatura inicial for igual à final isto indica que a compressão foi realizada de maneira adiabática, caso contrário, não. Para fazermos essa verificação em nosso sistema, o tempo de compressão e descompressão deveria ser da ordem de $4 \mathrm{~s}$ à $5 \mathrm{~s}$. Mas, infelizmente, esse tempo ainda é muito maior que o tempo de vida da armadilha magnética, nos impossibilitando de tal verificação.

Mesmo assim, podemos analisar as imagens da armadilha magnética e termos indícios de que possa haver compressão adiabática. Observando a figura 34, vemos que a distribuição dos átomos ao longo do potencial é alterada quando variamos a corrente que passa pelas bobinas de compressão. A distribuição passa de uma distribuição esférica a uma distribuição alongada até formar dois lóbulos. Se compararmos essa distribuição com os perfis de potencial que foram simulados, figuras 15, 16, 17 e 18, vemos que a distribuição de átomos está adaptando-se a 
esses perfis. Nas simulações, quando não há compressão, o perfil de campo é aproximadamente parabólico e, conforme vamos comprimindo o potencial, ocorre uma deformação do mesmo até formar um potencial com dois pontos de mínimo e um ponto de máximo local no centro desses dois pontos. Nas imagens, vemos claramente que a distribuição de átomos é, qualitativamente, idêntica ao perfil do potencial. Este são indícios de que possa ocorrer compressão adiabática em nosso sistema. Mas, infelizmente, não podemos ter certeza absoluta de tal fato.

Então, um dos próximos passos será a melhora da pressão parcial no interior da câmara para que possamos realizar a compressão adiabática. Feito isso, poderemos iniciar o resfriamento evaporativo e abaixar a temperatura até atingir o regime de CBE. Mas, antes de tudo, é preciso conhecer muito bem as características de nosso sistema. Este trabalho foi um passo fundamental na construção e na caracterização do sistema de aprisionamento magnético. Esperamos, com isso, termos dado uma contribuição pequena, mas importante, para a compreensão de sistemas tão complexos e fundamentais como é o caso da condensação de BoseEinstein. 


\section{VI - Referências}

[ 1 ] HUANG, K., Statistical Mechanics, Wiley, N.Y., 1963.

[2] BRADLEY, C.C.;SACKETT, C. A.; HULET, R.G. Phys. Rev. Lett., 78, 985 (1997).

[ 3 ] RASOLT, M; STEPHEN, M. H.; FISHER, M. E.; WEICHMAN, P.B. Phys. Rev. Lett. 53, 798 (1984).

[ 4 ] WOLFE, J. P.; LIN, J.L.; SNOKE, D.W. in Bose - Einstein Condensation, editado por GRIFFIN, A.; SNOKE, D. W.; STRINGARI, S. ( Cambridge University Press, Cambridge ) 281 (1995)

[ 5 ] FORTIN, E.; BENSON, E.; MYSYROWICZ, A. in Bose - Einstein Condensation, editado por GRIFFIN, A.; SNOKE, D. W.; STRINGARI, S. (Cambridge University Press, Cambridge) 519 (1995).

[6] ANDERSON, M. H. et al. Science 269, 198 (1995).

[ 7 ] BRADLEY, C. C. et al . Phys. Rev. Lett.75, 1687 (1995).

[ 8 ] DAVIS, K. et al . Phys. Rev. Lett. 75, 3969 (1995).

[ 9 ] FRIED, D. G. et al. . Phys. Rev. Lett 81, 3811 (1998)

[ 10 ] SILVEIRA, I. F.; WALRAVEN, J. T. M. Phys. Rev. Lett 44, 164 (1980).

[ 11 ] CLINE, R. W.; SMITH, D. A.; GREYTAK, T. J.; KLEPPNER, D. Phys. Rev. Lett 45, 2117 (1980).

[ 12 ] HECHT, C. E. Physica, 25, 1159 (1959).

[ 13 ] STWALlEY, W. C.; NOSANOW, L.H. Phys. Rev. Lett 36, 910 (1976)

[ 14 ] MigdalL, A. L. et al.. Phys. Rev. Lett 54, 2596 (1985).

[ 15 ] PHILliPS, W. D.; PRODAN, J.V.; METCALF, H.J. J. Opt . Soc . Am . B , 2, 1751 (1985).

[ 16 ] BERGEMAN, T.; EREZ, G.; METCALF, H. Phys. Rev. A, 35, 1535 (1987).

[ 17 ] PRITCHARD, D. E. Phys. Rev. Lett 51, 1336 (1983).

[ 18 ] WALRAVEN, J.T.M. in Quantun Dynamics of Simple Systems, editado por OPPO, G.L.; BARNETT, S.M.; RIIS, E.; WILKINSON, M. (Institute of Physics Publ. , London) 315 (1996).

[ 19 ] MAJORANA, E. Nuovo Cimento, 9, 43 (1932). 
[ 20 ] HESS, H.F. Phys. Rev. B, 34, 3476 (1986).

[ 21 ] MASUHARA, N. ef al. Phys, Rev. Lett 61, 935 (1988)

[ 22 ] STOOF, H.T.C.; KOELMAN, J.M.V.A.; VERHAAR, B.J. Phys. Rev. B,38, 4688 (1988).

[ 23 ] PRODAN, J.V.; PHILlIPS, W.D.; METCALF, H. Phys. Rev. Lett 49, 1149 (1982).

[ 24 ] COOK, R. J. Phys. Rev. A, 20, 224 (1979).

[ 25] MIRANDA, S.G.; MUNIZ, S.R.; TELLES, G.D.; MARCASSA, L.G.; HELMERSON, K.; BAGNATO, V.S. Phys. Rev. A, 59, 882 (1999).

[26] CHU, S. et al. Phys. Rev. Lett 55, 48 (1985).

[ 27 ] RAAB, E.L. et al. Phys. Rev. Lett 58, 2631 (1987)

[ 28 ] KETTERLE, W. et al. Phys. Rev. Lett 70, 2253 (1993).

[ 29 ] MEWES, M.O. et al. Phys. Rev. Lett 77, 416 (1996).

[ 30 ] MYATT, C.J. et al. Phys. Rev. Lett 78, 586 (1997).

[ 31 ] KETTERLE, W.; MEWES, M. O. LEOS Newsletter, IEEE, 18 - 21, August 1996 (1996).

[ 32 ] ESSLINGER, T.; BLOCH, I.; HÄNSCH, T. W. Phys. Rev. A, 58, R22 (1998).

[ 33 ] PRITCHARD, D. E. Phys. Rev. Lett 51, 1336 (1983)

[ 34 ] GOTT, Y. V.; IOFFE, M. S.; TEL'KOVSKII, V. G. Nuclear Fusion Supplement, 3, 1045 (1962).

[ 35 ] ERNST, U. et al., Europhys. Lett., 77, 416 (1996).

[ 36 ] BRADLEY, C.C.; SACKETT, C. A.; TOLleT, J. J.; HULET, R. G. Phys. Rev. Lett 75, 1687 (1995). 